\title{
Impact of food processing and detoxification treatments on mycotoxin contamination
}

\author{
Petr Karlovsky ${ }^{1} \cdot$ Michele Suman $^{2}$ • Franz Berthiller ${ }^{3}$ • Johan De Meester ${ }^{4}$. \\ Gerhard Eisenbrand $^{5}$ • Irène Perrin ${ }^{6}$ • Isabelle P. Oswald ${ }^{7,8} \cdot$ Gerrit Speijers $^{9}$. \\ Alessandro Chiodini ${ }^{10}$ - Tobias Recker $^{10} \cdot$ Pierre Dussort $^{10}$
}

Received: 14 April 2016/Revised: 29 July 2016/Accepted: 5 August 2016/Published online: 23 August 2016

(C) Society for Mycotoxin Research and Springer-Verlag Berlin Heidelberg 2016. This article is published with open access at Springerlink.com

\begin{abstract}
Mycotoxins are fungal metabolites commonly occurring in food, which pose a health risk to the consumer. Maximum levels for major mycotoxins allowed in food have been established worldwide. Good agricultural practices, plant disease management, and adequate storage conditions limit mycotoxin levels in the food chain yet do not eliminate mycotoxins completely. Food processing can further reduce mycotoxin levels by physical removal and decontamination by chemical or enzymatic transformation of mycotoxins into less toxic products. Physical removal of mycotoxins is very efficient: manual sorting of grains, nuts, and fruits by farmers as well as automatic sorting by the industry significantly lowers the mean mycotoxin content. Further processing such as milling, steeping, and extrusion can also reduce mycotoxin content. Mycotoxins can be detoxified chemically by reacting with food components and technical aids; these reactions are facilitated by high temperature and alkaline or acidic conditions. Detoxification of mycotoxins can also be achieved enzymatically. Some enzymes able to transform mycotoxins naturally occur in food commodities or are produced during fermentation but more efficient detoxification can be achieved by
\end{abstract}

Pierre Dussort

publications@ilsieurope.be

1 Molecular Phytopathology and Mycotoxin Research,

Georg-August-University Göttingen, Grisebachstrasse6,

37077 Göttingen, Germany

2 Barilla G. R. F.lli SpA, Advanced Laboratory Research, via Mantova 166, 43122 Parma, Italy

3 Christian Doppler Laboratory for Mycotoxin Metabolism, Department IFA-Tulln, University of Natural Resources and Life Sciences, Vienna, Konrad-Lorenz-Straße 20, 3430 Tulln, Austria

4 Cargill R\&D Center Europe, Havenstraat 84, B-1800 Vilvoorde, Belgium deliberate introduction of purified enzymes. We recommend integrating evaluation of processing technologies for their impact on mycotoxins into risk management. Processing steps proven to mitigate mycotoxin contamination should be used whenever necessary. Development of detoxification technologies for high-risk commodities should be a priority for research. While physical techniques currently offer the most efficient post-harvest reduction of mycotoxin content in food, biotechnology possesses the largest potential for future developments.

Keywords Mitigation - Natural toxins · Physical methods · Chemical treatment $\cdot$ Biological detoxification .

Decontamination

\section{Introduction}

Toxic secondary metabolites produced by fungi belong to the most toxic contaminants regularly occurring in a wide range of food commodities (Bennett and Klich 2003). Most

5 Department of Chemistry, Division of Food Chemistry and Toxicology, Germany (retired), University of Kaiserslautern, P.O.Box 3049, 67653 Kaiserslautern, Germany

6 Nestlé Research Center, Vers-chez-les-Blanc, PO Box 44, 1000 Lausanne 26, Switzerland

7 INRA, UMR 1331 ToxAlim, Research Center in Food Toxicology, 180 chemin de Tournefeuille, BP93173, 31027 Toulouse, France

8 Université de Toulouse, INP, UMR1331, Toxalim, Toulouse, France

9 General Health Effects Toxicology Safety Food (GETS), Winterkoning 7, 34353 RN Nieuwegein, The Netherlands

10 International Life Sciences Institute-ILSI Europe, Avenue E. Mounier 83, Box 6, 1200 Brussels, Belgium 
countries responded to this threat by establishing and enforcing maximum levels for mycotoxins in food (European Commission 2006; van Egmond et al. 2007). Setting maximum levels is based on toxicity assessment and exposure data but it also takes supply and demand into account. Raw materials are usually tolerated to have higher contamination levels (except for products intended for direct human consumption) than finished products. The rationale behind this is a dilution effect when formulating with noncontaminated ingredients in preparation of the final product as well as of the potential mitigation effects due to processing. In both cases, the mycotoxin concentration in the finished product will be lower than in the raw material.

Spoilage and toxin formation can occur already on the field and during storage of agricultural commodities or processed food. This article focuses on food, but results obtained on feed will be considered when they can be used to estimate the efficiency of mitigation strategies potentially useful for food. A variety of fungal species mostly from the genera Aspergillus, Penicillium, Fusarium, Alternaria, or Claviceps are known to produce mycotoxins. Most important in terms of toxicity and occurrence are aflatoxins $B_{1}, B_{2}, G_{1}$, and $G_{2}$ $\left(\mathrm{AFB}_{1}, \mathrm{AFB}_{2}, \mathrm{AG}_{1}, \mathrm{AFG}_{2}\right.$ ); ochratoxin A (OTA); fumonisins $\mathrm{B}_{1}, \mathrm{~B}_{2}$, and $\mathrm{B}_{3}\left(\mathrm{FB}_{1}, \mathrm{FB}_{2}, \mathrm{FB}_{3}\right)$; deoxynivalenol (DON) and other trichothecenes; zearalenone (ZEN); patulin (PAT); and ergot alkaloids (EAs), which are briefly characterized in Table 1, while their chemical structures are shown in Fig. 1.

Harmful effects of mycotoxin-contaminated food can be avoided by (i) preventing contamination, (ii) removing contaminated material from the food commodity, (iii) mitigating mycotoxin content in food, and (iv) treating exposed individuals. In some commodities, only part of the harvest enters the food chain. Selection of charges with low mycotoxin levels for consumption while using the remainder for feed and energy production would reduce the exposure of consumers to mycotoxins. Unfortunately, this is only possible in a few commodities and, even there, production systems targeting food markets, feed manufacturing, and energy production are often so specialized that they cannot replace each other. The first priority therefore remains prevention of toxin accumulation directly on the field (preharvest) or thereafter (transport and storage) (Kabak et al. 2006; Choudhari and Kumari 2010). A variety of agricultural practices, e.g., growing resistant crop varieties, crop rotation, soil tillage, chemical and biological control of plant diseases, and insect control are available to minimize mycotoxin production on the field (Edwards 2004; Munkvold 2014; Mesterhazy 2014; Alberts et al. 2016). Proper harvest and storage conditions are crucial to prevent fungal growth and mycotoxin accumulation in harvested commodities (Jacobsen 2014). Unfortunately, preharvest measures do not guarantee the absence of mycotoxins in food or feed. Food processing can impact mycotoxins in raw material by (i) physical removal, (ii) chemical transformation which can result in metabolites of lower or higher toxicity, (iii) release from masked or entrapped forms which may increase bioavailability, (iv) enzymatic detoxification, and (v) adsorption to solid surfaces. Physical and chemical mechanisms reducing mycotoxin content often act together in the same food processing step. For instance, sulfur dioxide used in corn wet milling to ease the separation of germs, proteins, and starch possesses potential for chemical detoxification. Reduction of mycotoxin contamination was documented for cleaning; milling; brewing; fermentation; cooking; baking; frying; roasting; flaking; alkaline cooking; nixtamalization (soaking, cooking in an alkaline solution, and hulling of grains); and extrusion. Concentrations of some mycotoxins can be reduced substantially while others, such as DON, are relatively resistant to degradation (Milani and Maleki 2014; Karlovsky 2011). Detoxification of grain mycotoxins during food processing has recently been reviewed (Kaushik 2015). As the last resort, consumers can be prophylactically treated with binders in areas of chronically high aflatoxin exposure (AfriyieGyawu et al. 2008; Wang et al. 2008).

The following terms are used to describe the outcome of mitigation treatments throughout this article: removal of mycotoxins from raw materials and/or finished products, transformation (modification of the chemical structure of the molecule), detoxification (transformation which reduced the toxicity), and decontamination (removal or detoxification/inactivation). Effective decontamination should be irreversible, modified forms of mycotoxins should be affected together with parent compounds, the products should be non-toxic, and the food should retain its nutritive value and remain palatable (Milani and Maleki 2014). Processing procedures, agents, and microorganisms must be allowed for use in food (Codex Alimentarius, 2015). The interested reader is also referred to European Commission Regulation 2015/786, defining acceptability criteria for detoxification processes applied to products intended for animal feed (EC 2015). These criteria may serve as a model for the assessment of mycotoxin detoxification technologies in food processing. Compliance of a given detoxification process with those criteria will be assessed by the European Food Safety Authority (EFSA).

In this review, conventional food processing affecting mycotoxins as well as processes dedicated to decontamination are covered. Applications of the techniques to selected commodities are presented for illustration, knowledge gaps are outlined, and recommendations for prioritizating mitigation actions and further research are given.

\section{Physical processing methods}

\section{Sorting}

Unprocessed cereals in bulk trading often contain dust and admixtures. Broken and damaged kernels usually contain most of mycotoxin contamination (Johansson et al. 2006) 
Table 1 Major mycotoxins and their producers, affected crops, adverse health effects and guidance values

\begin{tabular}{|c|c|c|c|c|}
\hline Mycotoxin & Major producing fungi & Main affected crops & Principal adverse effects & $\begin{array}{l}\text { Health-based guidance value } \\
\text { (HBGV) }\end{array}$ \\
\hline $\begin{array}{l}\text { Aflatoxins } \mathrm{FB}_{1} \\
\qquad \mathrm{FB}_{2}, \mathrm{FG}_{1}, \mathrm{FG}_{2} \\
\text { metabolite } \\
\mathrm{AFM}_{1} \text { in milk }\end{array}$ & $\begin{array}{l}\text { Aspergillus parasiticus, } \\
\quad \text { A. flavus (JECFA 2001a) }\end{array}$ & $\begin{array}{l}\text { Peanuts, nuts, maize, cottonseed, } \\
\text { wheat, barley, cocoa beans, rice, } \\
\text { copra, dried fruits, spices, figs, } \\
\text { crude vegetable oils (IARC 2012; } \\
\text { EFSA 2007; JECFA 1999) }\end{array}$ & $\begin{array}{l}\text { Extremely potent toxins and genotoxic } \\
\text { carcinogens (after metabolic } \\
\text { converstion to } 8,9 \text {-epoxides in the } \\
\text { liver); classified as carcinogenic to } \\
\text { humans, } \text { AFM }_{1} \text { as possibly } \\
\text { carcinogenic to humans (EFSA } \\
\text { 2007; IARC 2012; JECFA 1999, } \\
\text { 2001a) }\end{array}$ & $\begin{array}{l}\text { Because of carcinogencity, exposure } \\
\text { should be kept as low as reasonably } \\
\text { achievable. No official HBGV }\end{array}$ \\
\hline $\begin{array}{l}\text { Ochratoxin A } \\
\text { (OTA) }\end{array}$ & $\begin{array}{l}\text { Aspergillus alutaceus, } \\
\text { Aspergillus carbonarius, } \\
\text { Penicillium verrucosum } \\
\text { (EFSA 2006) }\end{array}$ & $\begin{array}{l}\text { Grain, legumes, oleaginous seeds, } \\
\text { peanuts, cashews, dried fruits, } \\
\text { coffee, wine, grape juice, cocoa, } \\
\text { spices, meat products (JECFA } \\
\text { 2001a; EFSA 2006) }\end{array}$ & $\begin{array}{l}\text { Nephrotoxic, renal tumors in rodents at } \\
\text { high doses (EFSA 2006, JECFA } \\
\text { 2001a, IARC 1993); classified as } \\
\text { carcinogenic in experimental } \\
\text { animals and possibly humans (IARC } \\
\text { 1993) }\end{array}$ & $\begin{array}{l}\text { PTWI } 120 \mathrm{ng} / \mathrm{kg} \mathrm{BW} / \text { day (EFSA 2006) } \\
\text { and } 100 \mathrm{ng} / \mathrm{kg} \mathrm{BW/day} \mathrm{(JECFA} \\
\text { 2001a) }\end{array}$ \\
\hline $\begin{array}{l}\text { Fumonisins } \mathrm{B}_{1} \text {, } \\
\mathrm{B}_{2} \text {, and } \mathrm{B}_{3} \\
\text { (FB1, FB2, } \\
\text { FB3) }\end{array}$ & $\begin{array}{l}\text { Fusarium verticillioides, } \\
\text { F. proliferatum, } \\
\text { Aspergillus niger (EFSA } \\
\text { 2005; JECFA 2001a, } \\
\text { 2012) }\end{array}$ & $\begin{array}{l}\text { Maize (Fusarium spp.), grapes } \\
\quad \text { (A. niger) (EFSA 2005; JECFA } \\
\text { 2001a, 2012) }\end{array}$ & $\begin{array}{l}\text { Inhibit sphingolipid biosynthesis; } \\
\text { induction of apoptosis, tumors in } \\
\text { rodents (EFSA 2005; JECFA 2001a; } \\
\text { SCF 2003, IARC 2002), putative } \\
\text { teratogenicity; FB } \text { F }_{1} \text { classified as } \\
\text { possibly carcinogenic to humans } \\
\text { (IARC 2002) }\end{array}$ & $\begin{array}{l}\text { Group PMTDI (JECFA 2001a, 2012) } \\
\text { and group TDI (SCF 2003) } 2 \mu \mathrm{g} / \mathrm{kg} \\
\text { BW/day for } \mathrm{FB}_{1}, \mathrm{FB}_{2} \text {, and } \mathrm{FB}_{3} \\
\text { alone or in combination }\end{array}$ \\
\hline $\begin{array}{l}\text { Deoxynivalenol } \\
\text { (DON) and its } \\
\text { acetylated deri- } \\
\text { vates (3- and } \\
\text { 15-acetyl- } \\
\text { DON) }\end{array}$ & $\begin{array}{l}\text { F. graminearum, } \\
\text { F. culmorum (EFSA } \\
\text { 2004, 2011a; JECFA } \\
\text { 2001a, 2011) }\end{array}$ & $\begin{array}{l}\text { Wheat, maize, barley, oats, rye; less } \\
\text { often rice, sorghum and triticale } \\
\text { (EFSA 2004, 2011a; JECFA } \\
\text { 2001a, 2011) }\end{array}$ & $\begin{array}{l}\text { Feed refusal, vomiting, and diarrhea; } \\
\text { reduced growth; thymus, spleen, } \\
\text { heart, liver, and immune system } \\
\text { affected at higher doses (EFSA } \\
\text { 2004; IARC 1993; JECFA 2001a; } \\
\text { SCF 2002); not classifiable as to } \\
\text { carcinogenicity to humans, (IARC } \\
\text { 1993) }\end{array}$ & $\begin{array}{l}\text { TDI } 1 \mu \mathrm{g} / \mathrm{kg} \text { BW/day for DON (SCF } \\
2002, \text { EFSA 2004); group PMTDI } \\
1 \mu \mathrm{g} / \mathrm{kg} \mathrm{BW/day;} \mathrm{ARfD} 8 \mu \mathrm{g} / \mathrm{kg} \\
\text { BW/day for DON and its acetylated } \\
\text { derivatives (JECFA 2011) }\end{array}$ \\
\hline $\begin{array}{l}\text { Other } \\
\text { trichothecenes, } \\
\text { e.g., T-2 toxin, } \\
\text { HT-2 toxin, } \\
\text { nivalenol } \\
\text { (NIV) }\end{array}$ & $\begin{array}{l}\text { F. sporotrichioides, } \\
\text { F. langsethiae (JECFA } \\
\text { 2001a), F. poae and } \\
\text { F. cerealis, F. culmorum } \\
\text { and F. graminearum } \\
\text { (EFSA 2013) }\end{array}$ & Cereals (EFSA 2011a) & $\begin{array}{l}\text { Acute effects of T-2 similar to high dose } \\
\text { radiation (diarrhea, hemorrhage, } \\
\text { hematotoxicity, and immune sup- } \\
\text { pression) (JECFA 2001a, EFSA } \\
\text { 2011a); toxicological profile of NIV } \\
\text { similar (EFSA 2013); not classifi- } \\
\text { able as to carcinogenicity to humans } \\
\text { (IARC 1993) }\end{array}$ & $\begin{array}{l}\text { Group TDI } 0.1 \mu \mathrm{g} / \mathrm{kg} \text { BW/day (EFSA } \\
2011 \mathrm{a} \text { ) and group PMTDI } 0.06 \mu \mathrm{g} / \\
\mathrm{kg} \text { BW/day (JECFA 2001a) for T- } 2 \\
\text { and HT-2 toxins combined. } \\
\text { TDI } 1.2 \mu \mathrm{g} / \mathrm{kg} \text { BW/day for NIV (EFSA } \\
2013 \text { ) }\end{array}$ \\
\hline $\begin{array}{l}\text { Zearalenone } \\
\quad(\text { ZEN) }\end{array}$ & $\begin{array}{l}\text { Fusarium spp. (JECFA } \\
\text { 2000, EFSA 2011b) }\end{array}$ & $\begin{array}{l}\text { Worldwide in all types of grains; } \\
\text { highest levels in maize and wheat } \\
\text { bran (JECFA 2000, EFSA 2011b) }\end{array}$ & $\begin{array}{l}\text { ZEN and its metabolites interact with } \\
\alpha \text { - and } \beta \text {-estrogen receptors and en- } \\
\text { docrine disruptors (JECFA 2000, } \\
\text { EFSA 2011b) }\end{array}$ & $\begin{array}{l}\text { PMTDI } 0.5 \mu \mathrm{g} / \mathrm{kg} \text { BW/day for ZEN, } \\
\text { recommended that the total intake of } \\
\text { ZEN and its metabolites should not } \\
\text { exceed the PMTDI (JECFA 2000); } \\
\text { TDI } 0.25 \mu \mathrm{g} / \mathrm{kg} \mathrm{BW} / \mathrm{d} \text { for ZEN } \\
\text { (EFSA 2011b) }\end{array}$ \\
\hline Patulin (PAT) & $\begin{array}{l}\text { Byssochlamys spp., } \\
\text { Penicillium spp., } \\
\text { Aspergillus spp. (IARC } \\
\text { 1986; JECFA 1996) }\end{array}$ & $\begin{array}{l}\text { Many fruits, strawberries, tomatoes, } \\
\text { olives, and cereals (IARC 1986; } \\
\text { JECFA 1996) }\end{array}$ & $\begin{array}{l}\text { Gastrointestinal ulceration; } \\
\text { immunotoxicity and neurotoxicity in } \\
\text { animals; genotoxic (JECFA 1996); } \\
\text { inadequate evidence of carcinoge- } \\
\text { nicity in animals, not classifiable as } \\
\text { to its carcinogenicity to humans } \\
\text { (IARC 1986) }\end{array}$ & $\begin{array}{l}\text { PMTDI } 0.4 \mu \mathrm{g} / \mathrm{kg} \text { BW/day (JECFA } \\
\text { 1996) }\end{array}$ \\
\hline Ergot alkaloids & $\begin{array}{l}\text { Claviceps spp., in Europe } \\
\text { mostly C. purpurea } \\
\text { (EFSA 2012, BfR 2004) }\end{array}$ & $\begin{array}{l}\text { True grasses; most important on } \\
\text { cereals (rye, wheat, triticale, } \\
\text { barley, millet, and oats) (EFSA } \\
\text { 2012, BfR 2004) }\end{array}$ & $\begin{array}{l}\text { Interact with neurotransmitter } \\
\text { receptors; acute toxicity: convulsive } \\
\text { neurotroxicity, uterine hemorrhage, } \\
\text { and abortions; chronic toxicity: } \\
\text { vasoconstriction with ischemia and } \\
\text { necrosis of extremities (ergotism) } \\
\text { (EFSA 2012, BfR 2004) }\end{array}$ & $\begin{array}{l}\text { Various EAs seem to have similar toxic } \\
\text { potency; group ARfD } 1 \mu \mathrm{g} / \mathrm{kg} \mathrm{BW} / \\
\text { day and group TDI } 0.6 \mu \mathrm{g} / \mathrm{kg} \mathrm{BW} / \\
\text { day; both apply to the sum of EAs } \\
\text { (EFSA 2012) }\end{array}$ \\
\hline
\end{tabular}

PTWI provisional tolerable weekly intake, $P M T D I$ provisional maximum tolerable daily intake, TDI tolerable daily intake, $A R f D$ acute reference dose (for 1-day exposure)

though they constitute only 3-6\% of the bulk load (Whitaker et al. 2003). The first processing of agricultural goods after harvest often involves sorting, washing, or milling (Grenier et al. 2014). Figure 2 summarizes the use of these techniques.
Sorting machines based on particle weight and size are in use since the end of the nineteenth century (Mayer 1898). Originally, grains were sorted in bulk using centrifugation force and flotation in air flow. In the 1960s, optical sorting 
Fig. 1 Chemical structures of major mycotoxins and modification due to food processing. 1 de-epoxidation, 2 acetylation, 3 oxidation, 4 epimerization, 5 deamination, 6 glucosylation, 7 hydrolysis, 8 lactone cleavage (hydrolysis), 9 hydroxylation, 10 peptide cleavage, 11 sulfonation, 12 reduction, 13 ether cleavage

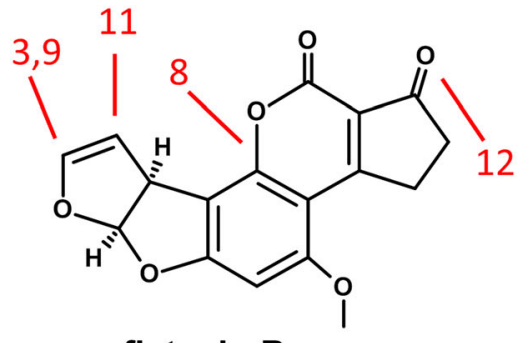<smiles>CC1(C)Cc2c(Cl)cc(C(=O)N[C@@H](Cc3ccccc3)C(=O)O)c(O)c2C(=O)O1</smiles>

aflatoxin $B_{1}$ ochratoxin A

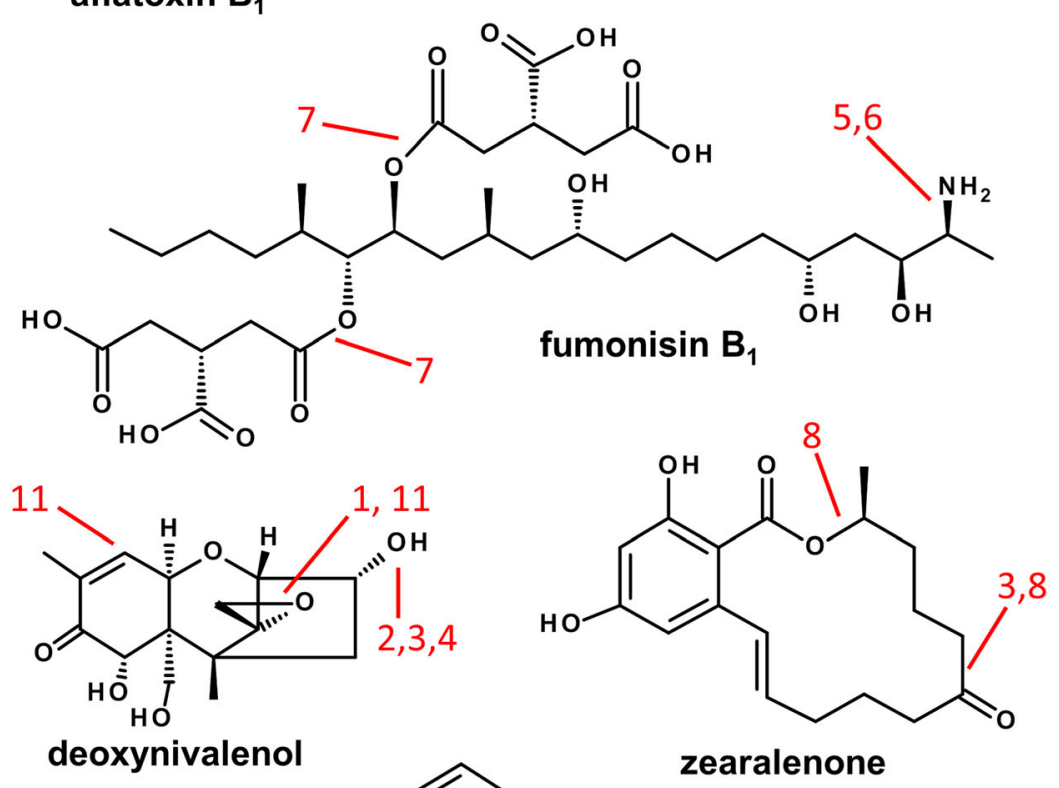<smiles>CCOC1=CCOC(O)(O)C1=CC(=O)O</smiles><smiles>c1ccccc1</smiles>

ergotamine<smiles>CCCC[C@H]1C(=O)N2CCC[C@H]2[C@@]2(O)O[C@](C)(NC(=O)[C@@H]3C=C4c5cccc6[nH]cc(c56)C[C@H]4N(C)C3)C(=O)N12</smiles>

was established. The operation principle is to direct streams of grains along an array of optical sensors. When a grain differing in color is detected, the detector triggers a magnetic valve and a jet of pressurized air removes the kernel from the stream (Fraenkel 1962). This principle is still used today. Contemporary grain sorters have a throughput of dozens of tons grain per hour.

Aflatoxin contamination is usually heterogeneous so that separating damaged kernels can effectively reduce contamination (Kabak et al. 2006). Grain sorting using UV light illumination for aflatoxin reduction is common. The observed bright greenish-yellow fluorescence (BGYF) does not originate from aflatoxins but from a kojic acid derivative following reaction with endogenous peroxidase. In dried commodities, peroxidase is inactivated and the BGYF method does not work.
The quick and easy "black light test" may therefore result in both false positive and false negative findings (Bothast and Hesseltine 1975). Although the test is not as reliable as originally hoped (Doster and Michailides 1998), it is widely used, e.g., by Turkish companies exporting dry figs and nuts to the EU. As an audition by the Food and Veterinary Office of the EU confirmed, the efficiency of sorting is regularly verified by laboratory analysis (EC 2013).

Distribution of ergot alkaloids (EAs) is even more heterogeneous than aflatoxins because intermediate contamination does not exist at a single-kernel level. Sclerotia loaded with EAs are efficiently removed from rye by opto-electronic sorting (Young et al. 1983; Miedaner and Geiger 2015).

Because infection with Fusarium verticillioides often does not cause symptoms (Munkvold and Desjardins 1988) and 
Fig. 2 Summary of physical and chemical processes applicable to food commodities in order to mitigate targeted mycotoxins. *Conversion to a more estrogenic cis-form. **Experimentally demonstrated on apple juice

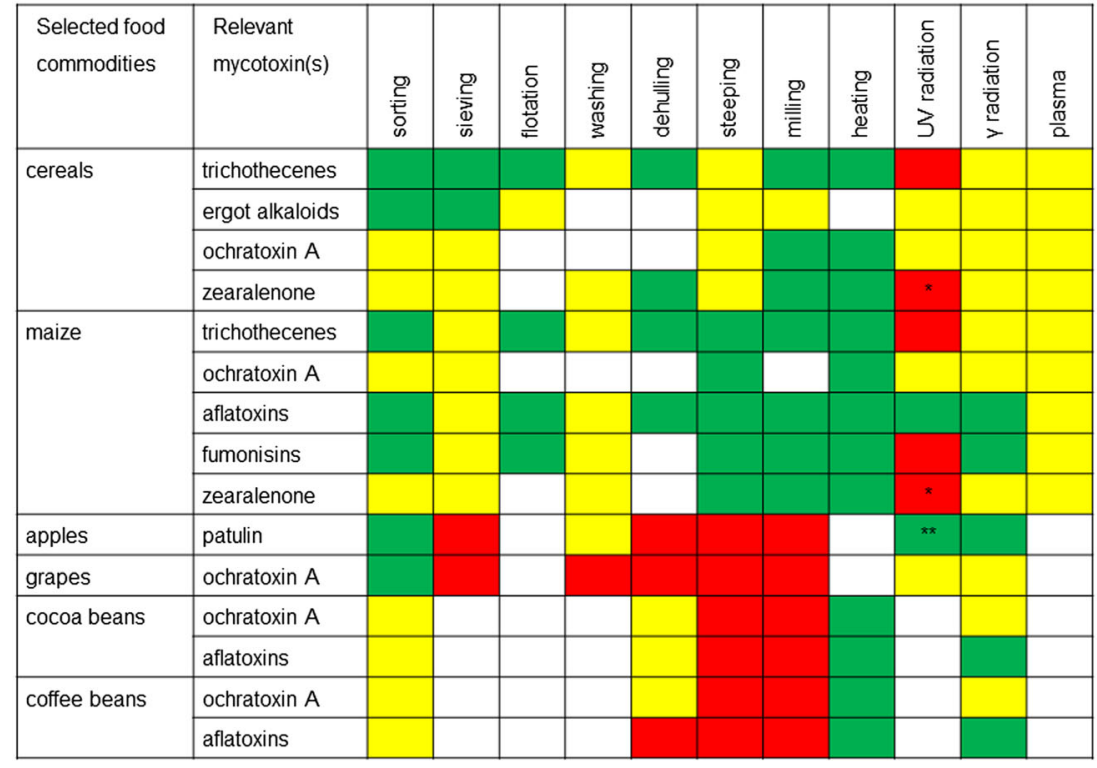

\begin{tabular}{|c|c|c|c|c|c|c|}
\hline $\begin{array}{l}\text { Selected food } \\
\text { commodities }\end{array}$ & $\begin{array}{l}\text { Relevant } \\
\text { mycotoxin(s) }\end{array}$ & $\frac{\overline{0}}{\mathrm{~d}}$ & 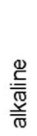 & $\begin{array}{l}\frac{}{0} \\
\frac{0}{0} \\
\frac{\pi}{x} \\
0\end{array}$ & $\begin{array}{l}\text { 들 } \\
\text { 음 } \\
\text { d }\end{array}$ & 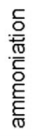 \\
\hline \multirow[t]{4}{*}{ cereals } & trichothecenes & & & & & \\
\hline & ergot alkaloids & & & & & \\
\hline & ochratoxin A & & & & & \\
\hline & zearalenone & & & & & \\
\hline \multirow[t]{5}{*}{ maize } & trichothecenes & & & & & \\
\hline & ochratoxin A & & & & & \\
\hline & aflatoxins & & & & & \\
\hline & fumonisins & & & & & \\
\hline & zearalenone & & & & & \\
\hline apples & patulin & & & & & \\
\hline grapes & ochratoxin A & & & & & \\
\hline \multirow[t]{2}{*}{ cocoa beans } & ochratoxin A & & & & & \\
\hline & aflatoxins & & & & & \\
\hline \multirow[t]{2}{*}{ coffee beans } & ochratoxin A & & & & & \\
\hline & aflatoxins & & & & & \\
\hline
\end{tabular}

\begin{tabular}{|l|l|}
\hline & Not possible or incompatible with the commodity \\
\hline & Partly successful or scientifically conceivable \\
\hline & Experimentally demonstrated \\
\hline & Not enough information or not applicable \\
\hline
\end{tabular}

correlation between fumonisin content and symptoms is weak (Afolabi et al. 2007), grain sorting might not reduce fumonisin content efficiently though successful attempts have been reported (Pearson et al. 2004). Mycotoxins accumulating without visible symptoms pose a limit to optical sorting as a mycotoxin mitigation strategy. This may explain why no reduction of aflatoxin content by sorting was found in a recent study (Mutiga et al. 2014).

\section{Sieving cleaning}

Removing kernels with extensive mold growth, broken kernels, and fine materials such as dirt and debris can be achieved by sieve cleaning, which significantly lowers total mycotoxin contamination. Removal of EAs from wheat grains by sieving has been used as a plant quarantine treatment (Muthaiyan 2009). After sieving off corn screenings, it was determined 
that intact kernels contained about 10 times less fumonisins than broken corn kernels or smaller parts (Murphy et al. 1993). Particles passing through a $3-\mathrm{mm}$ sieve usually constitute $5-20 \%$ of a sample by mass, but contain $26-69 \%$ of fumonisins (Sydenham et al. 1994). Removing broken kernels and smaller parts from maize reduced DON and ZEN contamination by around 70-80\%; however, up to $69 \%$ of the total maize was rejected as well (Trenholm et al. 1991). Losses of barley or wheat were lower with 34 and $55 \%$ for comparable mycotoxin reduction.

\section{Flotation and density segregation}

The different physical properties of mold-damaged kernels compared to non-damaged kernels can be exploited to separate them by density segregation or by fractionation on gravity tables. The damage to the kernels is caused by different fungi, rendering this techniques sensitive to the overall fungal contamination, rather than to specific toxins. Ergot containing EAs can be efficiently separated from rye grains by flotation in $\mathrm{NaCl}$ solution (Plante and Sutherland 1944). Removal of corn buoyant in water reduced aflatoxin levels by $60 \%$, at a mass loss of $22 \%$ (Huff 1980). Using a $30 \%$ sucrose solution, $87 \%$ aflatoxin reduction was achieved by the removal of $50 \%$ of the material (Huff 1980). Flotation on a saturated sodium chloride solution removed not only $3 \%$ of the kernels but also $74 \%$ of the total aflatoxin content in maize (Huff and Hagler 1985). Likewise, the removal of kernels floating on both water and $30 \%$ sucrose reduced more than $53 \%$ DON in maize and above $68 \%$ in wheat. The same procedure basically removed all ZEN in the tested samples (Huff and Hagler 1985). In a later study, fumonisin reduction of $86 \%$ was achieved by removing maize kernels buoyant in saturated brine, with about $20 \%$ material loss (Shetty and Bhat 1999).

\section{Washing}

Water-soluble mycotoxins can be partly washed from the surface of grains. ZEN is barely water-soluble, but well soluble in alkaline solutions. Therefore, sodium carbonate solutions are often used as an alternative to improve the effectiveness of washing steps. Washing barley and corn three times in distilled water reduced the DON content by $65-69 \%$, while ZEN concentrations were reduced by $2-61 \%$. Using $1 \mathrm{~mol} / \mathrm{l}$ sodium carbonate solution for the first wash step reduced DON by $72-75 \%$ and ZEN by $80-87 \%$ (Trenholm et al. 1992). In a similar study, the concentration of both toxins was reduced by $44 \%$ in corn by a single rinsing step with water. Additional soaking of the material in a $0.1 \mathrm{~mol} / \mathrm{l}$ aqueous sodium carbonate solution further reduced DON and ZEN concentrations by $35 \%$ (Rotter et al. 1995). As the soaking step took a full day, this technique should already be regarded as a chemical processing step (see next chapter). Washing and buoyancy techniques both suffer from the shortcoming that the grain must be dried after treatment before it can be stored. In order to ensure an efficient washing of contaminated commodities with water or water-based solutions, parameters such as partition coefficient or solubility should be considered and are given in Table 2.
Table 2 Hydrophobicity $(\log \mathrm{P})$ and solubility in water (in $\mathrm{mg} / \mathrm{l}$ ) of selected mycotoxins. Given data were gathered from databases using predictive tools

\begin{tabular}{|c|c|c|c|}
\hline Name & $\begin{array}{l}\text { predicted } \\
\log P^{*}\end{array}$ & $\begin{array}{l}\text { Predicted solubility in } \\
\text { water }(\mathrm{mg} / \mathrm{l})^{*}\end{array}$ & $\begin{array}{l}\text { Entry number in the toxin and toxin target } \\
\text { database (T3DB) }\end{array}$ \\
\hline Ochratoxin A & 3.66 & 25.6 & http://www.t3db.ca/toxins/T3D3605 \\
\hline Zearalenone & 3.04 & 117 & http://www.t3db.ca/toxins/T3D3665 \\
\hline Ergotamine & 2.95 & 223 & http://www.t3db.ca/toxins/T3D2460 \\
\hline $\mathrm{T}-2$ toxin & 1.95 & 347 & http://www.t3db.ca/toxins/T3D3664 \\
\hline HT-2 toxin & 1.32 & 1120 & http://www.t3db.ca/toxins/T3D3673 \\
\hline Aflatoxin $\mathrm{B}_{1}$ & 1.73 & 233 & http://www.t3db.ca/toxins/T3D3598 \\
\hline Aflatoxin $\mathrm{B}_{2}$ & 1.63 & 392 & http://www.t3db.ca/toxins/T3D3669 \\
\hline Aflatoxin $\mathrm{G}_{1}$ & 1.81 & 424 & http://www.t3db.ca/toxins/T3D3670 \\
\hline Aflatoxin $\mathrm{M}_{1}$ & 1.21 & 994 & http://www.t3db.ca/toxins/T3D3666 \\
\hline Citrinin & 1.23 & 1160 & http://www.t3db.ca/toxins/T3D3597 \\
\hline Patulin & -0.27 & 163,000 & http://www.t3db.ca/toxins/T3D3661 \\
\hline Deoxynivalenol & -0.76 & 36,000 & http://www.t3db.ca/toxins/T3D3668 \\
\hline Nivalenol & -0.79 & 64,600 & http://www.t3db.ca/toxins/T3D3674 \\
\hline Fumonisin $\mathrm{B}_{1}$ & -0.81 & $>20,000 * *$ & http://www.t3db.ca/toxins/T3D3603 \\
\hline Fumonisin $\mathrm{B}_{2}$ & -0.28 & $>20,000 * *$ & http://www.t3db.ca/toxins/T3D3697 \\
\hline
\end{tabular}

*Data from ALOGPS 2.0 (http://www.t3db.ca/toxins)

**Experimental data from the US National Toxicology Program (NTP 2000) 


\section{Dehulling}

The outer layers of grain are removed by dehulling techniques, which are formerly composed of an indispensable processing step prior to grinding. Limitation of fungal colonization and mycotoxin accumulation to surface layers of the kernel are prerequisites for the success of dehulling in mycotoxin content reduction (Vučković et al. 2013). This condition is fulfilled for aflatoxins in maize, dehulling of maize can therefore remove up to $93 \%$ of aflatoxins (Siwela et al. 2005). During the preparation of muthokoi, a traditional dehulled maize dish in Kenya, aflatoxin content was reduced by $46.6 \%$ (Mutungi et al. 2008), leading to significantly lower dietary exposure due to maize meal and muthokoi consumption as compared to the consumption of entire kernels (Kilonzo et al. 2014).

\section{Steeping}

This is the first step in wet milling of maize and involves soaking maize for $36-50 \mathrm{~h}$ at $50{ }^{\circ} \mathrm{C}$ in water containing 0.1 to $0.2 \% \mathrm{SO}_{2}$ to facilitate germ separation and breaking down of protein matrix. Adding $\mathrm{SO}_{2}$ also promotes lactic acid production which can be regarded as a chemical treatment from this review's perspective. Half of the aflatoxin content of corn was found in the steep liquor (Aly 2002). Fumonisins, which are highly polar, migrate from kernels into steeping water (Canela et al. 1996). Pujol et al. (1999) reported that steeping corn kernels in $0.2 \%$ solution of $\mathrm{SO}_{2}$ at $60{ }^{\circ} \mathrm{C}$ for $6 \mathrm{~h}$ was effective in reducing FB1. OTA was distributed equally between solubles and corn grits (Wood 1982). Steeping sorghum grains in $0.2 \% \mathrm{NaOH}$ reduced the concentration of aflatoxins, fumonisins, ZEN, and DON under detectable levels (Lefyedi and Taylor 2006).

\section{Milling}

After milling small-grain cereals, high mycotoxin levels are found in bran, such as DON, while finished flour is contaminated to a much lower degree (Cheli et al. 2013; Tibola et al. 2015). Spatial distribution of DON, ZEN, and their masked forms in wheat milling fractions was studied by SchwakeAnduschus et al. (2015). ZEN was concentrated in fiber-rich parts of grains DON contaminated all fractions equally, showing that the efficiency of milling as a mycotoxin mitigation strategy is limited to commodity/mycotoxin pairs in which mycotoxins are enriched in fractions that can be removed from processing.

Wet milling of maize results in germ (further processed into germ oil), starch, and gluten. Different mycotoxins accumulate in different fractions except for the starch fraction in which all mycotoxins are reduced below a level of concern. $40-50 \%$ of aflatoxins moved from corn into steep water in wet milling, 28-38\% remained in the fiber fraction, $11-17 \%$ in the gluten fraction, $6-11 \%$ in the germ, and only $1 \%$ in starch (Yahl et al. 1971; Bennett and Anderson 1978). Fumonisins are partly dissolved in steep water. At very high contamination levels, significant amounts of fumonisins remained in gluten and fiber. Germ fractions are less affected and starch is virtually free of fumonisins (Bennett et al. 1996). Two thirds of T-2 toxin were removed by steep and process water during wet milling of maize, starch contained $4 \%$ of the toxin and the remainder was evenly distributed between germ, gluten, and fiber (Collins and Rosen 1981). OTA present in steeped corn (see earlier) went into process water solubles and corn grits in almost equal amounts while only $4 \%$ were transferred to the germ (Wood 1982).

Dry milling of maize grain leads to concentration of mycotoxins in germ and bran fractions (Bullerman and Bianchini 2007). Aflatoxins are concentrated in germ fraction to a higher degree than fumonisins (Pietri et al. 2009). Increased concentrations of 16 Fusarium spp. mycotoxins in bran and germ as compared to whole grain were reported for dry-milled maize by Schollenberger et al. (2008). As expected, apolar ZEN was mainly found in germ and bran fractions after dry milling (Bennett et al. 1976). Milling results in redistribution of the ergot sclerotia with EAs among milling fractions (EFSA 2012).

\section{Heat treatment}

The time/temperature combination undoubtedly remains one of the most important interventions by which industrial processing can affect the mycotoxin content in a finished food product. Most mycotoxins are chemically and thermally stable though. While conventional food preparation with temperatures up to $100{ }^{\circ} \mathrm{C}$ have little effect on most mycotoxins, higher temperatures used in frying, roasting, toasting, and extrusion might reduce mycotoxin contamination.

Aflatoxins can be reduced by extrusion by $50-80 \%$, depending on grain moisture and temperature (Bullerman and Bianchini 2007). Alkaline treatment (see next chapter) can increase the efficacy of this process. Similar results were achieved for peanut meal, when extrusion alone reduced aflatoxins by $23-66 \%$ and up to $87 \%$ in the presence of ammonium hydroxide (Cheftel 1989). Roasting can reduce the levels of aflatoxins by $50-70 \%$ in peanuts and pecans and by $40-80 \%$ in maize (Conway et al. 1978). Pure aflatoxin $B_{1}$ $\left(\mathrm{AFB}_{1}\right)$ was destroyed by temperatures above $160{ }^{\circ} \mathrm{C}$; soybean matrix accelerated the process (Raters and Matissek 2008). Roasting can reduce the content of OTA in coffee beans by up to $97 \%$, depending on the temperature and particle size (Oliveira et al. 2013). Degradation of OTA in wheat by heating (Boudra et al. 1995) and extrusion (Scudamore et al. 2004) was less efficient. Thermal degradation products of OTA are 14-(R)-ochratoxin A, 14-decarboxy-ochratoxin A 
and ochratoxin alpha amide, all of which have reduced toxicity (Cramer et al. 2008; Bittner et al. 2015). Cazzaniga et al. (2001) reported drastic reduction of the level of DON under all investigated conditions but other labs found moderate effects depending on the conditions (Wu et al. 2011) or no reduction of DON and nivalenol (NIV) (Scudamore et al. 2008). Extrusion cooking of maize grits contaminated with ZEN reduced the toxin content by 65-83\% (Ryu et al. 1999). Extrusion or roasting was also effective in reducing fumonisins in maize grits by 34-95\% (Bullerman and Bianchini 2007). Increased temperature, decreased screw speed, and glucose addition resulted in higher reduction rates during extrusion. Thermal treatment always involves transformation reactions. Fumonisin in corn extruded with glucose (Bullerman and Bianchini 2007) yielded N-(1-deoxy-Dfructos-1-yl)-fumonisin $\mathrm{B}_{1}$, a compound less toxic than fumonisin $B_{1}$ to rats (Hahn et al. 2015). Citrinin (CIT) could also be efficiently degraded by heating (Trivede et al. 1992). EAs are partly degraded and epimerized during bread baking; the ratio between epimers shifts towards the -inine forms (EFSA 2012; Merkel et al. 2012).

\section{Irradiation}

Irradiation may be an approach for removing mycotoxins on an industrial scale, providing in fact energy to both food constituents and contaminants: reactions occur and change the molecular structure of food constituents. Non-ionizing (solar, $\mathrm{UV}$, microwave) and ionizing (gamma) radiations can reduce or eliminate pathogenic microorganisms, but partly also mycotoxins in food.

Photodegradation of aflatoxins in cereals has been found to decrease toxin levels by about $40 \%$ after $3 \mathrm{~h}$ and up to $75 \%$ after $30 \mathrm{~h}$ of direct sunlight (Herzallah et al. 2008). The same authors found sunlight to be more effective than $10 \mathrm{~min}$ of microwave heating (32\% reduction) or gamma-irradiation with $25 \mathrm{kGy}$ (43\% reduction). In another study, peanuts, pistachios, rice, and corn were irradiated with gamma radiation (Ghanem et al. 2008). At higher doses, the aflatoxin reduction was pronounced, reaching $59-88 \%$ at $10 \mathrm{kGy}$. However, the most recent study showed aflatoxin reductions of only $11-21 \%$ at $15 \mathrm{kGy}$ (di Stefano et al. 2014). The same study reported the reduction of OTA in almonds to $24 \%$ by gamma radiation at $15 \mathrm{kGy}$. This number is in good agreement with fumonisin reduction in maize, which was found to be about $20 \%$ after a dose of $15 \mathrm{kGy}$ (Visconti et al. 1996). Microwave treatment (and convection heat) was partially successful in lowering DON levels in naturally contaminated maize, with greatest effect occurring at the highest temperatures. With final temperatures of $150-175{ }^{\circ} \mathrm{C}$, a $40 \%$ reduction was achieved (Young 1986). This reduction can be explained by the formation of several nor-DONs, which are far less cytotoxic than DON (Bretz et al. 2006). Exposure of vegetable oil contaminated with ZEN to sunlight through common glass bottles caused isomerization of natural transZEN into cis-ZEN with a conversion of up to $90 \%$ (Köppen et al. 2012). UV light is very effective in removal of PAT in apple juice and cider. Evaluation of the reduction of PAT in apple juice at different wavelengths in the UVC range showed that $222 \mathrm{~nm}$ was most suitable (Zhu et al. 2014). At an initial level of about $1000 \mu \mathrm{g} / \mathrm{l}$, the UV exposure was successful in reducing PAT levels by 5 to $73 \%$, depending on the number of passes (Assatarakul et al. 2012). UV exposure, however, affected the taste of apple juice and cider.

\section{Cold plasma}

Cold plasma has strong antimicrobial effects and can be used to sterilize fragile or temperature-sensitive surfaces, such as food. A recent review on the use of plasma for food processing (Schlüter et al. 2013) highlighted the potential of this new technique that at the same time demands cautious use. No investigation on potential formation of toxic compounds by plasma treatment has been conducted yet. The authors concluded that plasma-treated products have to be assessed on a case by case basis for the time being.

Low-pressure cold plasma destroyed up to $50 \%$ of alfatoxins on nut surfaces (Basaran et al. 2008). The effect of atmospheric pressure argon cold plasma on spores and mycotoxin production of Aspergillus niger contaminating date palm fruits was recently evaluated (Ouf et al. 2015). After treatment for $9 \mathrm{~min}$, all fungal spores were killed, OTA and fumonisin $B_{2}$ contents dropped from 25 and $6 \mu \mathrm{g} / 100 \mathrm{~mm}^{2}$, respectively, below the limits of detection. Cold plasma generated by atmospheric dielectric barrier discharge in a direct and remote mode with synthetic air as working gas reduced the concentration of DON and ZEN in thin layers from $100 \mu \mathrm{g} / \mathrm{ml}$ to a few micrograms per milliliter (ten Bosch et al. 2014).

\section{Mycotoxin binders}

Mycotoxin binders are a physical technique used for feed decontamination (Jans et al. 2014) that principally can also be used in human intervention. Activated charcoal was used to remove patulin from naturally contaminated cider and bentonite removed $\mathrm{AFM}_{1}$ from naturally contaminated milk (Doyle et al. 1982). De Nijs et al. (2012) discussed the efficiency of mycotoxin mitigation and food safety aspects of such techniques. The efficiency of binders in mitigating adverse effects of aflatoxins in food was demonstrated in a randomized and double-blinded clinical trial (Wang et al. 2005; Afriyie-Gyawu et al. 2008; Wang et al. 2008). These are the only reports on the use of such techniques in food so far. 


\section{Chemical processing methods}

Many studies investigated chemical food processing methods for their suitability to destroy or inactivate mycotoxins. It should be noted that chemical treatment for the purpose of detoxification or decontamination is not authorized within the EU for commodities destined for human food; dedicated mitigation treatments would therefore require regulatory approval. Chemicals transform mycotoxins into other compounds, the toxicity of which must be assessed. It is furthermore crucial that the treatment does not impair nutritional quality, texture, or flavor of food. Criteria recently defined for the approval of detoxification techniques for feeds (EC 2015) may serve as a model for the development of corresponding regulations for food.

Common food processing technologies may reduce mycotoxin content as a side effect of accompanying chemical processes. Codex Alimentarius provides a list of such chemicals (Codex Alimentarius General Standard for Food Additives) and national legislations regulate their use. In this section, the effect of chemical treatments on mycotoxins in food will be reviewed regardless of whether the treatments are part of standard food processing or they have been studied as dedicated detoxification methods. The use of chemicals in combination with physical treatments, described in the previous section, may increases the efficacy of mycotoxin degradation. Chemical agents for mycotoxin detoxification can be applied by mixing, packing, fumigation or immersion.

\section{Acid treatment}

Most of the known mycotoxins are resistant against weak acids, as reviewed by Müller (1983). However, treatment of aflatoxins with strong acids destroyed the biological activity of $\mathrm{AFB}_{1}$ and $\mathrm{AFG}_{1}$ by converting them to hemiacetal forms $\mathrm{AFB}_{2 \mathrm{a}}$ and $\mathrm{AFG}_{2 \mathrm{a}}$, respectively (Ciegler and Peterson 1968; Dutton and Heathcote 1968). Treatment with $\mathrm{HCl}(\mathrm{pH} 2)$ reduced $\mathrm{AFB}_{1}$ levels by $19 \%$ within $24 \mathrm{~h}$ (Doyle et al. 1982). In the presence of acetic anhydride and hydrochloric acid, the reaction proceeds further to give the acetoxy derivative. Similar adducts of $\mathrm{AFB}_{1}$ and $\mathrm{AFG}_{1}$ are formed with formic acid-thionyl chloride, acetic acid-thionyl chloride, and trifluoroacetic acid. Aiko et al. (2016) treated aflatoxins with diluted acetic acid, citric acid, and lactic acid under conditions simulating cooking. Lactic acid was most efficient, converting $\mathrm{AFB}_{1}$ into $\mathrm{AFB}_{2}$ (traces) and $\mathrm{AFB}_{2 \mathrm{a}}$ (major product). Apart from detoxifying aflatoxins, small carboxylic acids inhibit mold growth, and are therefore used as preservatives.

\section{Treatment with bases}

Aflatoxins are unstable under alkaline conditions (Kiermeier and Ruffer 1974; Itoh et al. 1980), the first step of degradation being the opening of the lactone ring. Because this step is reversible, it is important to allow the reaction to proceed to completion. The degradation of aflatoxins in groundnut and cottonseed meal as well as in corn by sodium hydroxide and other alkaline reagents $\left(\mathrm{Ca}(\mathrm{OH})_{2}, \mathrm{Na}_{2} \mathrm{CO}_{3}, \mathrm{Na}_{3} \mathrm{PO}_{4}\right.$, methylamine, ethylene-diamine, ethanolamine) has been reviewed by Müller (1983). In most cases, a partial detoxification was achieved. Degradation of aflatoxins using ammonia has been extensively studied and proved effective in laboratory experiments as well as in field trials effective (Müller 1983; Park et al. 1988). Ammoniation of $\mathrm{AFB}_{1}$ resulted in two major breakdown products which retained the difuran moiety but lost the lactone ring: aflatoxin $\mathrm{D}_{1}$ and $\mathrm{D}_{2}$ [4-hydroxy-6methoxy-3a,8a-dihydrofuro[2,3]benzofuran] (Cucullu et al. 1976). Ammoniation decreased aflatoxin levels in maize by more than $75 \%$ (Park et al. 1988) and completely decomposed OTA in maize, wheat, and barley (Chełkowski et al. 1981). Ammoniation can reduce aflatoxin concentration by more than $99 \%$ (Chełkowski et al. 1981; Masri et al. 1969; Brekke et al. 1977). The efficacy of the process depends on the temperature, pressure, moisture, duration, and the substrate (Weng et al. 1994). Park et al. (1988) reviewed the decontamination of aflatoxins by ammoniation and concluded that the results demonstrate overwhelming support for the efficacy and safety of ammoniation as a practical solution to aflatoxin detoxification in oilseed meals intended for animal feeding. In spite of three decades of encouraging research, ammoniation of food commodities has, to our knowledge, not been approved in any country so far.

The instability of rubratoxin and cyclochlorotin under alkaline conditions was shown by Moss (1971) and Ishikawa et al. (1970), respectively. Chełkowski et al. (1981) demonstrated reduction of the content of penicillic acid, CIT, OTA, ZEN, and $\mathrm{AFB}_{1}$ after treatment with $2 \%$ aqueous $\mathrm{NH}_{3}$. PAT was unstable already at $\mathrm{pH} 7$, while at $\mathrm{pH} 8$, it was degraded completely after $190 \mathrm{~h}$ (Brackett and Marth 1979). Bennett et al. (1980) described $80 \%$ reduction of ZEN in spiked corn grits and $64 \%$ reduction in naturally contaminated corn after treatment with $3 \%$ $\mathrm{NH}_{3}$ at $50{ }^{\circ} \mathrm{C}$ for $16 \mathrm{~h}$.

Treatment of $\mathrm{FB}_{1}$-contaminated corn with $\mathrm{Ca}(\mathrm{OH})_{2}$, simulating nixtamalization (soaking/cooking in an alkaline solution), completely hydrolyzed $\mathrm{FB}_{1}$ but the toxicity of the products in brine shrimp assay was only partly reduced (Park et al. 1996). Ammoniation reduces the concentration of $\mathrm{FB}_{1}$ in wheat by $79 \%$ (Park et al. 1992) but was inefficient in corn according to Norred et al. (1991). Toxicity of the products of alkaline hydrolysis of fumonisins varies considerably among species (see enzymatic hydrolysis of fumonisins in the following section for details). Until these effects are fully understood, alkaline treatment of fumonisin-containing food ingredients should be avoided. 


\section{Use of oxidizing agents}

The oxidation of aflatoxin appears to be primarily an addition directed towards the double bond of the terminal furan ring, followed by subsequent reactions involving the phenol formed on opening the lactone ring. It was well-known that aflatoxins such as $\mathrm{AFB}_{1}, \mathrm{AFG}_{1}$, and $\mathrm{AFM}_{1}$, which had a terminal double bond in the dihydrofuran ring were more susceptible to attack by ozone $\left(\mathrm{O}_{3}\right)$ and other oxidizing agents than $\mathrm{AFB}_{2}, \mathrm{AFG}_{2}$, and $\mathrm{AFM}_{2}$, which lack this double bond (McKenzie et al. 1997). It is postulated that ozone reacts with the C8-C9 double bond of the furan ring of aflatoxin through electrophilic attack, causing the formation of primary ozonides followed by rearrangement into derivatives such as aldehydes, ketones, and organic acids (Proctor et al. 2004). Studies have demonstrated that ozone is able to degrade aflatoxins in different commodities (Dwarakanath et al. 1968) and in aqueous solutions (Maeba et al. 1988). $\mathrm{AFB}_{1}$ and $\mathrm{AFG}_{1}$ were sensitive to ozone and easily degraded with $1.1 \mathrm{mg} / \mathrm{l}$ of ozone within $5 \mathrm{~min}$ at room temperature. On the other hand, aflatoxins $\mathrm{B}_{2}\left(\mathrm{AFB}_{2}\right)$ and $\mathrm{G}_{2}\left(\mathrm{AFG}_{2}\right)$ were rather resistant to ozone, requiring 50-60 min to degrade them completely with $34.3 \mathrm{mg} / \mathrm{l}$ of ozone. These forms require longer exposure for detoxification; a possible mechanism is opening of the lactone ring (Samarajeewa et al. 1990).

Ozone was reported to reduce $\mathrm{AFB}_{1}$ and $\mathrm{AFG}_{1}$ levels by 77 and $80 \%$, respectively, in peanuts after treatment at $75^{\circ} \mathrm{C}$ for $10 \mathrm{~min}$, while the maximum degradation of $51 \%$ was achieved for $\mathrm{AFB}_{2}$ and $\mathrm{AFG}_{2}$ regardless of the exposure time (Proctor et al. 2004). In another study, the reductions of $\mathrm{AFB}_{1}$ in paprika were 80 and $93 \%$ after exposures to 33 and $66 \mathrm{mg} / 1$ $\mathrm{O}_{3}$ for $60 \mathrm{~min}$, respectively (Inan et al. 2007). Ozone degradation has been shown to be effective also against other mycotoxins such as DON (Young 1986, Young et al. 1986) and moniliformin (Zhang and Li 1994). A highly concentrated ozone produced by an electrochemical method (Rogers et al. 1992) was able to degrade and detoxify several mycotoxins in vitro, including aflatoxins, cyclopiazonic acid, OTA, PAT, secalonic acid D, and ZEN after treatment with $\mathrm{O}_{3}$ at $10 \%$ for $15 \mathrm{~s}$ (McKenzie et al. 1997).

Hydrogen peroxide, $\mathrm{H}_{2} \mathrm{O}_{2}$, was used on a commercial scale to detoxify aflatoxins. Treatment of figs with $\mathrm{H}_{2} \mathrm{O}_{2}$ at $0.2 \%$ caused a $66 \%$ reduction in $\mathrm{AFB}_{1}$ levels following 72-h storage (Altug et al. 1990). Hydrogen peroxide reduced aflatoxin concentrations in corn (Chakrabarti 1981), peanut meal (Sreenivasamurthy et al. 1967), and milk (Applebaum and Marth 1982). The concentration and the toxicity of ZEN decreased after treatment with aqueous solution of $\mathrm{H}_{2} \mathrm{O}_{2}$ (Lasztity et al. 1977). The efficiency of $\mathrm{H}_{2} \mathrm{O}_{2}$ for destruction of ZEN in contaminated corn was found to dependent upon the concentration of $\mathrm{H}_{2} \mathrm{O}_{2}$, temperature, and period of exposure (Abd Alla 1997). CIT was completely detoxified by $0.05 \% \mathrm{H}_{2} \mathrm{O}_{2}$ after 30 min whereas OTA was resistant to this treatment (Fouler et al. 1994).
Matsuura et al. (1979) reported that ZEN is destroyed by oxidation with ammonium persulfate. Natarajan et al. (1974) showed that sodium hypochlorite concentration and $\mathrm{pH}$, but not temperature and time, affected the destruction of aflatoxins in peanut protein. Aflatoxin degradation by sodium hypochlorite was compared with the effect of sodium hydroxide and ammonium hydroxide (Draughon and Childs 1982). All three treatments significantly reduced fluorescence but the survival of brine shrimp has not always increased. The mutagenic and cancerogenic aflatoxin $\mathrm{B}_{1}$-2,3-dichloride may be formed using sodium hypochlorite, although this can be avoided by adding acetone (Castegnaro et al. 1981). Aflatoxins were removed completely from rice meal treated with $16.5 \% \mathrm{NaCl}$ and $1 \% \mathrm{NaOCl}$ for $24 \mathrm{~h}$ (Okonko and Nwokolo 1978).

\section{Treatment with reducing agents}

Sodium bisulfite $\left(\mathrm{NaHSO}_{3}\right)$ was shown to destroy mycotoxins, primarily $\mathrm{AFB}_{1}$ in maize (Doyle et al. 1982) and dried figs (Altug et al. 1990). Dried fig fruits were spiked to contain $250 \mu \mathrm{g} / \mathrm{kg} \mathrm{AFB}$ and treated with sodium bisulfite (1\% in the aqueous phase). This treatment caused $28 \%$ of added toxin to degrade within $72 \mathrm{~h}$ at $25{ }^{\circ} \mathrm{C}$. When $0.2 \% \mathrm{H}_{2} \mathrm{O}_{2}$ were added 10 min before the bisulfite treatment, $65 \%$ of $\mathrm{AFB}_{1}$ were degraded in $72 \mathrm{~h}$. Heating bisulfite-treated samples at 45 to $65^{\circ} \mathrm{C}$ for $1 \mathrm{~h}$ caused up to $68 \%$ of added $\mathrm{AFB}_{1}$ to be degraded. Promising results have been achieved in $\mathrm{AFB}_{1}, \mathrm{AFG}_{1}$, and $\mathrm{AFM}_{1}$ detoxification using sodium bisulfite (Doyle and Marth 1978a, b; Moerck et al. 1980; Hagler et al. 1982; Yagen et al. 1989). Moerck et al. (1980) and Hagler et al. (1982) demonstrated efficient destruction of low and high levels of aflatoxin in corn. The decontaminated corn had improved color, better palatability, better handling properties, improved economics, and the residual bisulfite was a permitted food additive. Yagen et al. (1989) established the structure of aflatoxin $\mathrm{B}_{1} \mathrm{~S}$ as $15 \alpha$ sodium sulfonate of $\mathrm{AFB}_{1}$. The formation of $\mathrm{AFB}_{1}$ products substituted at the 15 th position only is unprecedented and implies an unusual mechanism. The completeness of the reaction and the water solubility of aflatoxin $\mathrm{B}_{1} \mathrm{~S}$ supports the use of bisulfite as a promising method to mitigate $\mathrm{AFB}_{1}$ and $\mathrm{AFG}_{1}$.

$\mathrm{NaHSO}_{3}$ solutions reduced DON in contaminated maize ( $4.4 \mathrm{mg} / \mathrm{kg}$ ) by $85 \%$ after $18 \mathrm{~h}$ at $80^{\circ} \mathrm{C}$ (Young et al. 1987). Sodium metabisulfite at $10 \mathrm{~g} / \mathrm{kg}$ was reported to overcome the depressing effect of DON on feed intake in piglets (Dänicke et al. 2005). Reduction of DON in animal feed by treatment with sodium bisulfite and sodium metabisulfite has been demonstrated in several studies. The treatment leads to the formation of less toxic DON sulfonate; a review is available (Dänicke et al. 2012). Later, it was discovered that the use of different sulfur reagents for reduction of DON yielded three different DON sulfonates with the same mass and molecular 
formula (Schwartz et al. 2013). DON sulfonate 1 is characterized by loss of the epoxide group, and DON sulfonate 2 by formation of a hemiketal. DON sulfonate 3 is an equilibrating mixture of two isomers, a ketone and a hemiketal. Rapid formation of DON sulfonates 1 and 2 occurs at alkaline $\mathrm{pH}$, slow formation of DON sulfonate 3 takes place at acidic $\mathrm{pH}$, irrespective of the sulfur reagent used. Whereas DON sulfonates 1 and 2 are stable across a broad $\mathrm{pH}$ range, DON sulfonate 3 decomposes to DON and DON sulfonates 1 and 2 at alkaline pH (Schwartz et al. 2013).

\section{Treatment with food ingredients and medical plants}

Certain spices, herbs, and other ingredients used in food production and home cooking were shown to detoxify mycotoxins. Incubation with extract of ajwan (carom), used as a spice in Asian cooking, destroyed aflatoxins (Velazhahan et al. 2010). Extracts of medicinal plants Ocimum tenuiflorum detoxified aflatoxins even at room temperature (Panda and Mehta 2013) and aqueous extracts of vasaka leaves (Adhatoda vasica) degraded $\mathrm{AFB}_{1}$ completely after $24 \mathrm{~h}$ at $37^{\circ} \mathrm{C}$ (Vijayanandraj et al. 2014). Detoxification of aflatoxins by Indian spices and herbs was recently reviewed (Aiko and Mehta 2015). Reducing sugars such as D-glucose and D-fructose blocked the primary amino group of $\mathrm{FB}_{1}$, after incubation at $65^{\circ} \mathrm{C}$ for $48 \mathrm{~h}$, preventing $\mathrm{FB}_{1}$-induced toxicity on cell tissue cultures on rats and swine (FernandezSurumay et al. 2005).

\section{Enzymatic detoxification}

\section{Distinguishing features of enzymatic detoxification}

Enzymatic catalysis takes a unique position among activities potentially suitable to detoxify mycotoxins. A distinguishing feature of enzymatic detoxification is its specificity. Notable exceptions are laccases and peroxidases, which have been tested for degradation of mycotoxins (Alberts et al. 2009; Wang et al. 2011) though they modify a wide range of substrates and may thus destroy valuable food components. The potential of enzymatic activities for the detoxification of mycotoxins in general was recently reviewed (Vanhoutte et al. 2016) but only a single short review is available on the potentical of enzymatic detoxification of mycotoxins in food production (Karlovsky 2014).

Enzymes are proteins and, when used in food processing, may cause allergy. However investigation of the allergenic potential is part of the documentation required for the approval of enzymes as additives or processing aids (EFSA 2009; JECFA 2001b). No allergic reaction to current food enzymes has been reported so far, indicating that enzymes are of limited concern regarding food allergies (Bindslev-Jensen et al. 2006). Because of their specificity and favorable toxicological profile, enzymes possess a yet unexplored potential to detoxify organic contaminants in food. A recent application pointing the way is the use of recombinant asparaginase to prevent formation of acrylamide in bread (Hong et al. 2014). No enzyme has so far been authorized in the EU for the reduction of mycotoxin contamination in food.

\section{Intentional use of enzymes to detoxify mycotoxins in food production}

Enzymes are used extensively as processing aids. For instance, recombinant aspartic protease chymosin is an alternative to rennet in the manufacturing of cheese (Teuber 1993) and industrial enzymes of five classes are used in bread making (Whitehurst and van Oort 2010). Malting and brewing are further examples of processes that would benefit from the use of enzymes detoxifying mycotoxins. Beer is commonly contaminated with DON (see section "Ethanol and beer"). Adding enzymes detoxifying DON to amylases, glucanases, proteases, and other enzymes used in beer production (Whitehurst and van Oort 2010) is compatible with brewing technologies. Unfortunately, enzymes suitable for irreversible detoxification of DON are not available yet. Promising new detoxification activities have been identified (Ito et al. 2013; He et al. 2015); it remains to be seen whether enzymes responsible for these activities are suitable for industrial production.

DON is a major mycotoxin contaminating wheat. Because the same mycotoxin occurs in beer and wheat flour, enzymes envisaged for the detoxification of DON in beer might be suitable for bakery products, too. Such an enzyme could be added to wheat flour together with recombinant xylanases, proteases, amylases, and other enzymes commonly used in the process.

Another example of the potential of industrial enzymes to reduce exposure to mycotoxins is the detoxification of PAT. Fruit juices and particularly purees may contain PAT. Production of juices involves treatment with pectinases/ arabanases, glucoamylases, and other enzymes. Enzymatic activities degrading PAT have been found in many species of bacteria and yeast (for instance, Zhu et al. 2015b). Degradation products are less toxic (Castoria et al. 2011; Zhu et al. 2015a), indicating that mitigation of PAT by enzymes is feasible. At least one of the enzymes detoxifying PAT does not require diffusible cofactors and is active in semi-purified form (Zhu et al. 2015a). Degradation of PAT can likely be combined with current enzymatic treatments used in the production of fruit juices and purees.

Widespread use of enzymes in food processing suggests that detoxification of mycotoxins by enzymatic treatment is compatible with current food technologies. 


\section{Examples of enzymatic activities suitable for the detoxification of mycotoxins in food processing}

Because fumonisins cause severe, species-specific diseases in farm animals (Voss et al. 2007) and are presumably also in humans (Isaacson 2005), extensive research on fumonisin detoxification has been carried out (Alberts et al. 2016). Enzymes detoxifying fumonisins were found in black yeast Exophiala spinifera (Blackwell et al. 1999) and genetically engineered maize varieties detoxifying fumonisins by enzymes of the yeast were developed (Duvick 2001). Fumonisin-detoxifying bacterium Sphingomonas spp. was characterized (Heinl et al. 2010) to provide enzymes for the decontamination in animal feeds; applications of these enzymes in food production are explicitly considered in the pertaining patent. Fumonisins are polyketides possessing an amino group and esterified with two carballylic acid residues. Microbial degradation of fumonisins is initiated by the hydrolysis of the ester bonds, which reduced the toxicity of fumonisins in pigs (Grenier et al. 2012) but not in rats (Seiferlein et al. 2007). Biochemical studies showed that hydrolyzed fumonisins might be transformed to highly toxic derivatives in vivo (Humpf et al. 1998), which might account for species differences in the toxicity of hydrolyzed fumonisins.

It was shown already in 1988 that the fungus Clonostachys rosea (syn. Gliocladium roseum) is capable to metabolize ZEN in high yield (el-Sharkawy and Abul-Hajj 1988) to a less estrogenic product. Two groups identified the $C$. rosea gene encoding a ZEN-specific hydrolase (Takahashi-Ando et al. 2002; Karlovsky et al. 2003). The enzyme does not require cofactors and appears suitable for food processing. Further activities detoxifying ZEN have been found in yeasts, bacteria, and fungi (Vekiru et al. 2010; Tan et al. 2014; Popiel et al. 2014).

Numerous enzymes degrading OTA have been described (Abrunhosa et al. 2010). Because OTA is an amide, many peptidases are able to hydrolyze this mycotoxin, including carboxypeptidase and chymotrypsin (Pitout 1969). Numerous lipases were shown to hydrolyze OTA, too (Stander et al. 2000). An enzyme from A. niger cleaves OTA into less toxic OT $\alpha$ and phenylalanine (Dobritzsch et al. 2014).

Enzymatic detoxification appears conceivable for any mycotoxin but a proof of concept for food processing is yet to be provided.

\section{Microbial decontamination}

\section{Detoxification of mycotoxins as a side effect of fermentation}

Fermentation is food processing with the help of microorganisms. Activities of bacteria and fungi used in fermentations are responsible for desired transformations of food components but hundreds of additional enzymatic activities are present in their cells, actively secreted into food matrix or released from disintegrated cells after autolysis. Some of these activities may transform mycotoxins into non-toxic products (Wolf-Hall and Schwarz 2002) but no microbial strain has been authorized so far as a processing aid targeting mycotoxins. Malting and brewing are prominent examples of technologies that may benefit from such fermentation aids. Considering how much beer per capita is consumed in industrial countries, beer contributes significantly to exposure of consumers to DON and ZEN (see section "Ethanol and beer"). Detoxification of several mycotoxins during malting has been documented, including complete loss of OTA and CIT (see section "Ethanol and beer") and loss of most of EAs during malting and brewing (Schwarz et al. 2007) but DON survives the process (Scott 1996).

Manufacturing of many dairy products involves fermentation with lactic acid bacteria. The major mycotoxin of concern in milk is aflatoxin $\mathrm{M}_{1}$ (see section "Milk and other dairy products"). Detoxification of aflatoxins by lactic acid bacteria has been studied for three decades (Megalla and Mohran 1984). Unfortunately, we still do not know whether the loss of aflatoxins observed after incubation with lactic bacteria is caused by adsorption, as shown for some lactobacteria (Pierides et al. 2000; Haskard et al. 2001), or whether irreversible enzymatic transformations occurred. This question has not been rigorously addressed so far in spite of its eminent relevance for food safety.

Cultures of yeast Saccharomyces cerevisiae are used in wine making, brewery, and sour dough production. S. cerevisiae was shown to detoxify the mycotoxins PAT (Moss and Long 2002) and OTA (Petruzzi et al. 2014). Alcoholic fermentation of fruit juices destroys PAT, therefore fermented products such as cider and perry will not contain PAT (FAO/WHO 2003). Products of the transformation of ZEN by S. cerevisiae retain their estrogenicity (Matsuura and Yoshizawa 1985; Böswald et al. 1995). Other mycotoxins such as fumonisins and some trichothecenes are not affected by fermentation (Bothast et al. 1992; Schwartz et al. 1995).

An example of technology with potential to reduce mycotoxin content by fermentation is the production of tempeh in Indonesia. Tempeh is traditionally made of soybean fermented with Rhizopus oligosporus. Some current forms of tempeh contain maize and groundnuts, which are prone to contamination with aflatoxins. Interestingly, Rhizopus spp. strains were reported to detoxify aflatoxins (Nakazato et al. 1990). The safety of tempeh can possibly be improved by selecting starter cultures that detoxify aflatoxins without any modification of the technology.

\section{Detoxification of mycotoxins by pure microbial cultures with potential for applications in food production}

Except for Rhizopus spp., the ability of food-grade microbial strains to detoxify mycotoxins is limited. Most toxicologically relevant mycotoxins are not detoxified by microbial species 
used in fermentation. Active strains have to be isolated from other sources. The first screening for mycotoxin-degrading microbes was carried out in the 1960s in the US Department of Agriculture, targeting aflatoxins (Ciegler et al. 1966). Many promising activities were reported but the results were rarely confirmed and advanced. Physical adsorption and enzymatic degradation were seldom differentiated. The unsatisfactory state of knowledge is reminiscent of the removal of aflatoxins by lactic acid bacteria. Numerous further bacterial and fungal species were identified in screening for the detoxification of aflatoxins but progress in elucidating mechanisms of their action was slow. It took 34 years to obtain indication that detoxification of aflatoxins by Flavobacterium aurantiacum is enzymatic (Smiley and Draughon 2000) yet the mechanism is still not known. New microorganisms removing mycotoxins from culture supernatant are continuously being described but follow-up studies are often missing. Degradation of $\mathrm{AFB}_{1}$ by Rhodococcus erythropolis, reported by Teniola et al. (2005) and Alberts et al. (2006) 10 years ago, is a typical example. It is to be hoped that the recent discovery of aflatoxin detoxification by Rhizopus oryzae and Trichoderma reesei (Hackbart et al. 2014) will not share this fate.

In some systems, studies of detoxification of mycotoxins at a molecular level revealed that the activities are not suitable for food processing. This applies in particular to the degradation of $\mathrm{AFB}_{1}$ by Actinomycetes sp. (Ciegler et al. 1966, Hormisch et al. 2004, Teniola et al. 2005, Alberts et al. 2006). The enzymes responsible for aflatoxin degradation in these bacteria are reductases depending on cofactor $F_{420}$, which does not occur in microorganisms used in food processing (Taylor et al. 2010). Anaerobic de-epoxidation of trichothecenes by ruminal and intestinal microflora is another example. The activity is known since 1983 (Yoshizawa et al. 1983), the first active pure culture was obtained in 1997 (Binder et al. 1997) but the mechanism and enzyme(s) involved remain unknown.

Yeast used to protect fruits from fungal spoilage may enzymatically destroy the mycotoxin PAT, produced by Penicillium species in infected fruits. Rhodosporidium paludigenum, which is a yeast species studied for fruit protection, degrades PAT into less toxic desoxypatulinic acid (Zhu et al. 2015a). However, treatment of infected apples and pears with $R$. paludigenum increased the PAT content of the fruits, probably by triggering a stress response in PAT producers (Zhu et al. 2015b). Caution is therefore advised when biological control agents are applied to food commodities. Another example of potentially undesirable side effects of biological control provides ZEN. Because the mycotoxin protects its producer against mycoparasites and competitors (Utermark and Karlovsky 2007), applications of biological control agents to grain contaminated with ZEN-producing Fusarium species might induce increased ZEN production.
Laccases and peroxidases can degrade diverse organic compounds. Degradation products of aflatoxins by peroxidase from white-rot fungus Phanerochaete sordida were elucidated (Wang et al. 2011). In most cases, however, the mechanisms of detoxification remained unknown. For instance, Alberts et al. (2009) demonstrated degradation of $\mathrm{AFB}_{1}$ by laccases of several fungal species and showed that the products were not mutagenic but they have not determined their structures.

The list of microorganisms reported to detoxify mycotoxins is long; we refer to reviews on microbial degradation of mycotoxins in general (Karlovsky 1999; McCormick 2013; Hathout and Aly 2014) and on trichothecenes (He et al. 2010; Karlovsky 2011). New detoxification mechanisms for DON have been discovered recently (Ikunaga et al. 2011; Ito et al. 2013; He et al. 2015, 2016). Although the enzymes involved are still unknown, the use of these strains for the decontamination of food commodities appears promising. As holds for all microorganisms used in food processing, microbial strains for mycotoxin mitigation in food would require regulatory approval.

\section{Commodities}

In this section, examples of raw materials and commodities are given that suffer from high mycotoxin contamination and for which mitigation strategies were studied.

\section{Cereals and derived products}

Cereals are staple food worldwide. They are the primary source of carbohydrates and the main source of foodborne mycotoxin exposure. The degree of fungal penetration into the endosperm of grains is reflected in the redistribution of mycotoxins in milling fractions (see section "Physical processing methods"). Due to high mycotoxin concentrations in surface tissues of grains afflicted with Fusarium head Blight, sorting, cleaning, dehulling, and debranning reduce mycotoxin contamination of the flour. A large fraction of mycotoxins can be removed with damaged kernels, fine material, and dust (Cheli et al. 2013). The efficiency of such cleaning in mycotoxin reduction was demonstrated for T-2 and HT-2 toxins (Schwake-Anduschus et al. 2010), fumonisins (Saunders et al. 2001), and DON (Lancova et al. 2008a). Scudamore and Patel (2000) reported effect of cleaning on the content of aflatoxins and fumonisins. In the last decade, several authors reported DON reduction through debranning (e.g., Aureli and D'Egidio 2007). The concept was extended to masked mycotoxins such as DON-3-glucoside (Kostelanska et al. 2011). Recently, the fate of fumonisins along the entire corn meal production chain has been elucidated (Generotti et al. 2015b). Fumonisin content decreased by $40 \%$ in 
cornmeal semolina; the reduction was less pronounced in corn flour and middlings.

Aflatoxins in cereal matrix can be reduced by soaking (with or without organic acids), cooking/heating, or steaming (Samarajeewa et al. 1990). Ordinary cooking of rice contaminated with $\mathrm{AFB}_{1}$ resulted in a reduction of $34 \%$; more than $70 \%$ were destroyed by pressure cooking (Park and Kim 2006). The reduction of aflatoxin content by extrusion depends on the presence of additives, moisture level and the applied temperature/pressure; an efficiency of 50 to $80 \%$ can be achieved. Similar effects were reported for OTA in bakery products (Scudamore et al. 2004).

Nixtamalization, which hydrolyzes ester bonds of fumonisins, reduced $\mathrm{FB}_{1}$ content of tortillas by $82 \%$ (Dombrink-Kurtzman et al. 2000). Mycotoxins were retrieved mainly in the steeping and washing water.

Gamma and electron-beam irradiation was evaluated for the reduction of trichothecenes in grains (O'Neill et al. 1993). DON and 3-acetyl-DON were more efficiently destroyed in aqueous solution than on maize kernels.

The effect of bread baking on DON is controversial. While reduction by more than $50 \%$ was observed in one study (Voss and Snook 2010), no changes in DON concentrations during baking was reported by others (Lancova et al. 2008a). The effect of the fermentation of dough on mycotoxins was also evaluated by Vidal et al. (2014). OTA remained stable, whereas DON concentration increased from unkneaded mix to fermented dough and decreased during baking. Zachariasova et al. (2012) observed the opposite: DON concentration decreased from flour to fermented dough and increased during baking. Other authors (Bergamini et al. 2010; Suman et al. 2012, 2014; Generotti et al. 2015a) confirmed the reduction of DON content during baking with the help of a Design of Experiments approach in a pilot plant and industrial production for bread, rusks, and crackers. Baking time and temperature were the key factors of DON reduction. Protease and xylanase used in the bakery industry released additional DON from the matrix during kneading and fermentation of dough (Simsek et al. 2012).

ZEN was reported to remain stable during bread baking (Cano-Sancho et al. 2013) but another study estimated ca. $40 \%$ loss in bread and $20 \%$ in biscuits (Alldrick and Hajšelová 2004). Numanoglu et al. (2013) constructed a kinetic model of ZEN degradation in maize bread during baking.

Nivalenol degradation accelerated with increasing bakery processing temperature (Bretz et al. 2005). Degradation of T-2 and HT- 2 toxins by $20-30 \%$ during bread baking was reported (Monaci et al. 2011) but no degradation was observed in another study (Schwake-Anduschus et al. 2010).

As shown earlier, studies of the fate of DON, ZEN, and T-2 during baking within the last 30 years left contradictory conclusions. Results on fumonisins are less extensive but equally contradictory. The first study, conducted more than 20 years ago, reported high losses of fumonisins in heated corn (Scott and Lawrence 1994). A more recent study (Numanoglu et al. 2010) found no significant reduction in the content of DON, ZEN, and fumonisins in traditionally produced Turkish maize bread. Finally, (Bryła et al. 2014) demonstrated reduction of fumonisins by $30 \%$ during baking of gluten-free bread.

Studies of the fate of the depsipeptide mycotoxins enniatins (ENNs) and beauvericin (BEA) during processing of cereals are limited. Vaclavikova et al. (2013) showed that ENNs levels dropped during bread baking to $30 \%$. Meca et al. (2012) observed BEA degradation from 20 to $90 \%$ in crispy breads during heat treatment and fermentation.

Ergot alkaloids in cereals attract increasing attention of food safety authorities (EFSA 2012). Reduction of sclerotia by up to $80 \%$ can be achieved by winnowing previous to the milling, resulting in substantial reduction of ergot alkaloid content (Berg et al. 1995). Recent incidents of contamination with ergot alkaloids above tolerable levels were reported particularly in small (organic) enterprises (Masloff 2006). An explanation is that equipment for optical sorting is too expensive for small enterprises (Dusemund et al. 2006). Processing sclerotia-contaminated flour in bread, pancakes, or noodles result in a loss of the toxicologically relevant (R)-isomers. Complete decomposition of (R)-isomers of six predominant ergot alkaloids was observed during baking of whole wheat bread, whereas rye bread and triticale pancakes retained 85 and $74 \%$ of these compounds, respectively (Scott and Lawrence 1982). A recent work on biscuits reported degradation and epimerization of up to $30 \%$ ergot alkaloids to less toxic forms (Merkel et al. 2012).

In pasta, the solubility of mycotoxins in boiling water determines the level of consumer exposure. According to Visconti et al. (2004), most DON was extracted from pasta to cooking water. Brera et al. (2013) observed DON reduction in semolina in dry and cooked pasta by 8 and $41 \%$, respectively.

\section{Cocoa-chocolate}

Cocoa is grown in West Africa, Asia, and Latin America mainly as raw material for chocolate production. Suboptimal storage and processing conditions in producing areas frequently cause fungal contaminations producing aflatoxins and OTA (Copetti et al. 2014). In order to minimize the OTA contamination of cocoa, cocoa-producing countries are developing new post-harvest treatment guidelines. OTA is concentrated in beans shells and therefore toxin levels in the nibs are low: mechanical shelling removed $48 \%$ of OTA (Gilmour and Lindblom 2008), while shelling by hand reduced OTA to between 50 and $100 \%$ (Amezqueta et al. 2005).

The first step of cocoa processing is opening the harvested pods at the farm site; then, the beans are fermented naturally 
by yeasts and bacteria. Experiments in Brazil (Copetti et al. 2012) demonstrated the importance of organic acids produced by fermentative bacteria in suppressing the growth of fungi with the potential to produce OTA. Fermented beans are dried in the sun on wooden platforms or on the ground. The OTA level significantly increases during transition from fermentation to drying (Dano et al. 2013). Drying must be therefore conducted as rapidly as possible. In processing plants, dried beans are broken and winnowed to obtain de-shelled kernels (nibs). The nib is sterilized with steam and roasted directly without (natural) or with addition of alkali to develop the final flavor and color. The temperature reaches 100 to $120^{\circ} \mathrm{C}$ for a period of 15 to $70 \mathrm{~min}$; it is not expected that OTA is degraded significantly in this step (Mounjouenpou et al. 2012). However, degradation of OTA by 17 to $40 \%$ was reported in different experiments (Manda et al. 2009; Copetti et al. 2013).

The effect of roasting on aflatoxins in cocoa was evaluated by Mendez-Albores et al. (2013); roasting cocoa beans at $250{ }^{\circ} \mathrm{C}$ for $15 \mathrm{~min}$ reduced aflatoxin content by up to $71 \%$. Mycotoxin levels in alkalized cocoa powder tend to be reduced (Copetti et al. 2011; Turcotte et al. 2013). Alkalization appeared to be more effective in reducing aflatoxin than OTA. Results of Mendez-Albores et al. (2013) showed reduction in aflatoxin content in cocoa liquors due to the thermal-alkaline treatment up to $98 \%$. Turcotte et al. (2013) reported that OTA and $\mathrm{AFB}_{1}$ occurred ubiquitously in natural and alkalized cocoa, decreasing progressively from cocoa liquor to baking chocolate, to dark chocolate, and milk chocolate; no OTA was found in cocoa butter. Overall, it can be inferred that processing cocoa bean to chocolate leaves negligible concentrations of OTA and aflatoxins in the final product. In addition to the degradation described earlier, production of chocolate includes addition of other ingredients (e.g., milk products and sugars) which further dilutes mycotoxins in the final commodity.

The European Commission currently considers that introducing maximum limit of OTA in cocoa or cocoa products does not appear necessary for the protection of public health (European Commission (EC) Regulation No. 1881/2006). Indeed, samples of cocoa containing more than $2 \mathrm{ng} / \mathrm{g}$ of these mycotoxins can rarely be found.

\section{Coffee}

Green coffee beans are one of numerous food commodities significantly contaminated with OTA (Speijers and van Egmond 1993). Coffee and cocoa beans are hygroscropic and thus vulnerable to contamination with OTA during storage and transport (Magan and Aldred 2005). Scudamore (2005) reviewed the effect of roasting and brewing of coffee on the level of OTA as compared to green coffee beans. OTA levels were drastically reduced during production of soluble coffee. The roast and the ground of coffee contained only
$16 \%$ of the concentration found in raw green coffee beans (Blanc et al. 1998). Similarly, Milanez (1996) reported $84 \%$ of OTA reduction in processed beans. However, other investigators found lower OTA reduction (Leoni et al. 2000).

\section{Fruit juices}

The major mycotoxin in fruit juices is PAT. The starting point of reducing PAT in apple-derived products is the selection of intact apples and the removal of rotten apples. Several studies have shown that PAT is stable in slightly acidic apple and grape juices but is decomposed during the production of cider (Moss and Long 2002). Alcoholic fermentation converts PAT into ascladiol, which is less toxic than PAT (Suzuki et al. 1971). A number of studies on the effect of different physical, chemical, or microbiological food processes on PAT concentrations have been performed (Leggett et al. 2001; Castoria et al. 2011; Zhu et al. 2015b). PAT reacts with sulfhydryl (thiol) groups of proteins, polypeptides, and amino acids available in certain food commodities such as cereals to form intra- and intermolecular protein cross links. These PAT adducts are not detected by conventional methods for PAT analysis (Fliege and Metzler 1999).

\section{Milk and other dairy products}

$\mathrm{AFB}_{1}$ contaminating dairy feed may be metabolized in the animal into its monohydroxy derivative form aflatoxin $\mathrm{M}_{1}$ which is carried over into milk (Holzapfel et al. 1966). $\mathrm{AFM}_{1}$ or its metabolites can then contaminate subsequent dairy products. Distribution and stability of $\mathrm{AFM}_{1}$ during processing, ripening, and storage of Telemes cheese was studied by Govaris et al. (2001). Concentration of $\mathrm{AFM}_{1}$ in the curds was about four times higher than in milk but it fell in the cheese during ripening. In certain cheese kinds in Turkey, the concentration of $\mathrm{AFM}_{1}$ was, however, higher in the cheese than in bulk milk (Bakiri 2001). Fermentation of milk to yogurt at $\mathrm{pH} 4.6$ and 4.0 reduced $\mathrm{AFM}_{1}$ concentration by 13 and $22 \%$, respectively; total loss of $\mathrm{AFM}_{1}$ after storage was 16 and $34 \%$, respectively (Govaris et al. 2002). In opposition with these findings, Yousef and Marth (1989) reported that $\mathrm{AFM}_{1}$ in fermented milk remained stable. Separation of milk components partitioned the toxin in accordance with its affinity for casein and the lack of solubility in fats.

\section{Vegetable oils}

Mahoney and Molyneux (2010) assumed that aflatoxins are not found in vegetable oils but there is increasing evidence that this does not apply to non-purified or crude vegetable oils (Shephard et al. 2011). High incidences of aflatoxin contaminations in edible vegetable oils were even reported (Bordin et al. 2014). The different processes used for vegetable oil 
extraction may partially explain these discrepancies. Edible vegetable oils indeed can be extracted from oleaginous material either by mechanical pressing or by solvents.

Distribution of mycotoxins from steeped corn to corn germs in wet milling depends on their solubility. Watersoluble mycotoxins such as DON were found at high concentrations in steep liquor but at low levels in the solid (germ, fiber, and gluten) fractions. The inverse is true for ZEN, which is relatively insoluble in water (Table 2). ZEN may occur in maize germ oil but investigations about the effect of processing of oils on ZEN are limited, except for UV light exposure during storage (see section "Irradiation"). Abalaka and Elegbede (1982) reported that only 10-20\% of aflatoxins were transferred from groundnuts and cotton seeds to crude oil. Similarly, Parker and Melnick (1966) found most aflatoxins after extraction of oil from peanut and maize in defatted meal. In their work, corn oil extracted with chloroform contained more aflatoxins than oil extracted with hexane. Refining based on alkaline neutralization, washing, bleaching, and deodorization was reported to remove mycotoxins from oil (Kamimura et al. 1986). There are no studies in the literature relating degumming to the presence of aflatoxins.

In the deacidification step of refining, fatty acids are removed using an alkali (chemical refining) or water vapor (physical refining). Alkaline treatment is effective in degrading aflatoxins (see section "Treatment with bases"). Kamimura et al. (1986) evaluated the efficiency of the processing steps of refining vegetable oils contaminated with mycotoxins and observed that after treatment with sodium hydroxide, $\mathrm{AFB}_{1}$ and $\mathrm{AFB}_{2}$ were significantly reduced, $\mathrm{DON}$ and NIV were present only in traces and $\mathrm{AFG}_{1}$ and $\mathrm{AFG}_{2}$ were completely eliminated. These results confirmed an earlier finding by Parker and Melnick (1966) that sodium hydroxide efficiently removed aflatoxins from peanut oil. ZEN is removed below a level of concern from corn germ oil by alkaline treatment at pH 9-10 (Slope et al. 2013).

Bleaching consists of introducing an adsorptive bleaching material, called bleaching earth or clay, under vacuum condition and high temperature, and subsequent removal of the agent by filtration. Parker and Melnick (1966) found that bleaching reduced aflatoxin levels in peanut and corn oils below $1 \mu \mathrm{g} / \mathrm{L}$. Kamimura et al. (1986) reported that bleaching of vegetable oil eliminated trichothecenes and aflatoxins but not ZEN.

The last step of the refining process of vegetable oil is the deodorization step, which is a codistillation process using water vapor under high temperature $\left(220-270{ }^{\circ} \mathrm{C}\right)$ and low pressure $(0.1-0.7 \mathrm{kPa})$. Conditions adopted in the deodorizing process can lead to complete removal of aflatoxins from vegetable oils, as Kamimura et al. (1986) showed for artificially contaminated vegetable oils. The levels of trichothecene and ZEN were reduced, too. Thus, it is possible to ensure safe edible vegetable oil provided it is properly processed.

\section{Ethanol and beer}

In process where fermentation is followed by distillation, mycotoxins are not present in the alcohol fraction but may be increased in the spent grain product. $\mathrm{AFB}_{1}$ was decreased by $47 \%$ after cooking and fermenting contaminated corn or wheat (Dam et al. 1977), although its concentration in the solids after distillation was higher than in the starting grain. No ZEN from contaminated corn appeared in ethanol but ZEN concentration in the solids after fermentation doubled. Two lots of corn contaminated with 15 and $36 \mathrm{mg} / \mathrm{kg}$ of $\mathrm{FB}_{1}$ were fermented for ethanol production (Bothast et al. 1992). Analysis of the various fermentation products showed that there was little fumonisin degradation during fermentation. No $\mathrm{FB}_{1}$ was found in distilled ethanol or centrifuged solids. Most of the fumonisins were distributed over distillers' dried grains, thin stillage, and distillers' solubles.

Most mycotoxins can survive brewing and end up in the beer; DON is found at highest concentrations (Scott 1996). Lancova et al. (2008b), however, reported that even larger amounts of DON in beer were present in the form of DON3-glucoside. Schwartz et al. (1995) found that in the brewing process both ZEN and 15-acetyl-DON increased during germination of barley. Eighty to $93 \%$ of DON from malt grist was found in the beer; $60 \%$ of ZEN and $18 \%$ of 15 -acetylDON were found in the spent grains. Scott and Lawrence (1995) examined the losses of OTA as well as of $\mathrm{FB}_{1}$ and $\mathrm{FB}_{2}$ in fermentation of wort. Up to $21 \%$ of OTA but negligible amounts of fumonisins were taken up by the yeast, indicating that OTA and fumonisins could contaminate beer. Fumonisins were later indeed detected in domestic and imported beer in Canada (Scott et al. 1993). Most recently, the fate of 14 mycotoxins during beer brewing was investigated by Inoue et al. (2013). After brewing, the levels of aflatoxins, OTA, $\mathrm{FB}_{2}$, PAT, and ZEN dropped below $20 \%$. ZEN and PAT were apparently metabolized to less toxic compounds. Trichothecenes survived brewing at more than $50 \%$ of their initial concentration. Vaclavikova et al. (2013) reported that enniatins from contaminated wheat and barley were not transferred into beer; these hydrophobic mycotoxins remained adsorbed on spent grain.

\section{Dried fruits, nuts, and spices}

Food safety is significantly affected by mycotoxin contamination of dried fruits, nuts, and spices. Dry fruits such as raisins, sultanas, figs, apricots, and dates are consumed worldwide. Cultivation and processing of these fruits in warm climates rise mycotoxin risk, especially concerning aflatoxins and ochratoxin $\mathrm{A}$. The $\mathrm{pH}$ of fruits ranging from 2.5 to 5.0 is the most important factor affecting spoilage of fruits by microorganisms. Fruits become increasingly susceptible to fungal invasion during ripening, as the $\mathrm{pH}$ of the tissue increases and skin 
layers soften (Drusch and Ragab 2003). Other factors contamination level are harvesting and drying conditions and moisture content (Bullerman et al. 1984). Physical cleaning and separation, where the mold-damaged $\mathrm{kernel} / \mathrm{seed} /$ nuts are removed, can result in 40-80 \% reduction in aflatoxin level. Dry and wet milling may redistribute aflatoxins into less utilized fractions.

In groundnuts, higher levels of aflatoxin are associated with small, immature pods. Removing these pods reduces aflatoxin concentration in shelled lots (Dorner 2008). To remove foreign material and unshelled pods, shelled peanuts are subjected to gravity separation. Because highly contaminated kernels are less dense, this process reduces aflatoxin contamination (Davidson et al. 1981). Shelled kernels can be further separated by size through a series of slotted screens; generally, aflatoxins are associated with smaller-sized kernels (Whitaker et al. 2005). Further, aflatoxin reduction can be obtained by blanching combined with electronic color sorting (Cole et al. 1995) and sorting with the help of IR and UV spectroscopy (Durmus and Kalkan 2016). Blanching and color sorting is used for other nuts such as pistachios, too.

Among dried fruits, figs are the most challenging. Removal of damaged fruits, solar drying, fluorescence sorting, and treatment with sulfur dioxide are effective mycotoxin mitigation strategies (Scott and Trucksess 2009). Sun-drying figs are often practiced in tropical countries but because it is slow, it allows proliferation of molds producing mycotoxins. Ozay et al. (1995) showed that dipping figs in solution of metabisulfite or sorbate or in hot water followed by dehydration reduced fungal colonization and aflatoxin content. Comparison of different drying systems with sun-drying revealed that ultrasound treatment combined with osmotic solutions is most effective (Villalobos et al. 2016).

Very recently, the use of cold atmospheric plasma to destroy aflatoxins in dehulled hazelnuts was reported, with over $70 \%$ aflatoxin reduction achieved by $12 \mathrm{~min}$ of treatment (Siciliano et al. 2016). Another recent work demonstrated that roasting pistachio nuts with lemon juice and/or citric acid destroyed over $90 \%$ AFB1 (Rastegar et al. 2016).

To the best of our knowledge, the effect of food processing on mycotoxin levels in spices was not studied. A moderate reduction of OTA and aflatoxin content in pepper by gamma radiation was reported (Jalili et al. 2012).

\section{Implications and outlook}

Mycotoxin contamination of food commodities, especially of staple foods, poses a serious threat to human health. Efficient reduction of mycotoxin exposure via food products requires the utilization of all available technologies from good agricultural and storages practices and selection of raw materials suitable for human consumption to the application of food processing technologies including biotechnology. Today's consumers are keenly aware of the importance of food for their health. Their perception of food safety has been heavily biased towards man-made pollutants but toxic compounds of natural origin are slowly gaining attention. Food industry has recognized the trend, as intellectual property protection efforts in mycotoxin detoxification show (He and Zhou 2010).

Mitigation of mycotoxins as a side effect of established food processing techniques, such as fermentation of apple juice or nixtamalization of maize flour, should be utilized whenever possible. Development of new techniques dedicated to mycotoxin mitigation will, however, require extensive research. The impact of mycotoxin mitigation processes on the nutritional composition and organoleptic quality of food and their influence on other contaminants such as acrylamide (Anese et al. 2009) have to be assessed. The advantage of reducing mycotoxin levels has to be weighed against the loss of material and/or nutrients. Novel physical and chemical treatments (cold plasma) and novel detoxification agents (microbes or purified enzymes) for mycotoxin mitigation in food would have to undergo regulatory approval, which implies a risk analysis. European regulation 1881/ 2006 provides direction in what is likely to be acceptable; similar regulations operate outside Europe (refer also to EC regulation 2015/786).

Disappearance of a parent mycotoxin does not necessarily mean detoxification, if the toxin is converted into a form that escapes detection, yet remains toxic. Often, the mechanism of mycotoxin transformation is not fully understood, the products have not been characterized, and their bioavailability and toxicity compared to the parent compound has not been assessed. Limited toxicological investigations on mycotoxin degradation products were restricted to in vitro and acute in vivo studies which provide insufficient information regarding the safety at chronic low level exposure. New predictive tools in toxicology (Schilter et al. 2014; Kavlock et al. 2012; Cozzini and Dellafiora 2012) may be helpful in identifying transformation or degradation products requiring detailed toxicological investigation. Without such knowledge and as a precautionary approach, risk assessment has to assume that all mycotoxin forms have the same bioavailability and toxicity as the respective parent compound (EFSA 2014).

While detoxification of mycotoxins has been studied extensively, little is known about the potential of food processing to increase or hide mycotoxin exposure. Chemical and physical treatments applied to food may release mycotoxins from masked forms and make them bioavailable or convert mycotoxins into forms not detectable by conventional analytical methods (Rychlik et al. 2014) while retaining their toxic potential (Suman and Generotti 2015) or stimulate contaminating fungi to mycotoxin production, e.g., during steeping of barley. Analytical tools for mycotoxins transformed by processing (structural modification, binding to food matrix) need to be developed. 
Most research on mycotoxins focused on regulated mycotoxins. The recent unexpected discovery of the fungus Stachybotrys chartarum in culinary herbs (Biermaier et al. 2015) showed that the scope has to be broadened: S. chartarum, so far known mainly from water-damaged walls, produces macrocyclic trichothecenes of higher acute toxicity than any regulated mycotoxin. Highly toxic metabolites of the fungus Stenocarpella maydis recently discovered in maize grains provide another example of toxicologically relevant nonregulated mycotoxins in food (Rogers et al. 2014). Even wellstudied fungal metabolites may raise new food safety concerns, such as AAL toxin of Alternaria alternata if it occurs in tomato juice (Karlovsky 2016). Genome sequencing revealed that fungicontaminating food commodities have the potential to produce 30-60 secondary metabolites each, some of which might turn out to be mycotoxins. Mitigation strategies have to be adapted to newly discovered mycotoxins, once their toxicity and level of exposure have been assessed. Undoubtedly, the list of regulated mycotoxins will grow.

The large number of combinations of processing/commodities/mycotoxins calls for prioritization among applications on which to focus further research efforts. Criteria for prioritization should be consumption of the contaminated commodity (staple foods and commodities consumed by sensitive population groups like young children), occurrence at high levels in such commodities and unfavorable toxicological profiles. Different geographical regions and target groups require different prioritizations. An example is fumonisin contamination of maize: in Africa, maize is a staple food, causing human exposure to fumonisins that would exceed the tolerable daily intake (TDI) even if EU limits of contamination could be achieved (Shephard et al. 2007; JECFA 2012). Celiac disease patients in industrialized countries consume above-average amounts of maize; it was shown that their dietary exposure to fumonisins clearly exceeds average levels (Dall'Asta et al. 2012). Most consumers in Europe, however, would not exceed TDI for fumonisins even if they consume maize exceeding the EU limit by an order of magnitude. Guidelines have been elaborated on how to identify relevant targets for mitigation, determine the effectiveness of mitigation measures, and assess the risk of unintended consequences (van der Fels-Klerx et al. 2014).

\section{Conclusions}

Food processing can reduce mycotoxin exposure by destroying or eliminating mycotoxins, by transforming them into less toxic derivatives, by adsorbing mycotoxins to solid surfaces or by reducing their bioavailability due to chemical attachment to food matrix structures. Complete elimination of mycotoxins from food product by processing can rarely be achieved.
Several processing techniques of proven value (mostly physical treatments) have been in use for a long time. These are the only mycotoxin mitigation methods currently applicable to human food. Few chemical and biotechnological techniques reducing mycotoxin content have been approved for animal feed but many promising strategies remain at an experimental stage. In addition to mycotoxin derivatives modified by microorganisms or plants (EFSA 2014), the risk assessment of mycotoxins in food has to include mycotoxin forms resulting from food processing. Before a novel mycotoxin decontamination technique is approved, chemical identity and toxicity of the reaction products have to be determined. Availability of analytical methods which permit reliable detection of these products is a key prerequisite for risk assessment. Bioavailability and toxicity of transformation products should be assessed using a systematic approach and generally acknowledged testing systems. This in turn allows prioritizing those which require more detailed toxicological assessment and the choice of specific, adequate risk assessment options. Recently established legislative criteria for detoxification processes applied to feed may serve as a model (EC 2015). In the absence of adequate toxicological data, mycotoxin forms generated during processing must be assumed to have the same toxicity, bioavailability and carcinogenic potency as the respective parent compounds. The development of mitigation strategies should prioritize mycotoxins that regularly occur at high levels in highly consumed commodities and have unfavorable toxicological profiles. The ultimate goal of mycotoxin mitigation is to prevent adverse health effects caused by foodborne exposure to mycotoxins while preserving nutritional and organoleptic quality of food.

Source of funding This work was commissioned by the Processrelated Compounds and Natural Toxins Task Force of the European branch of the International Life Sciences Institute (ILSI Europe). Industry members of this task force (2013-2016) are Abbott Nutrition, ADM, Barilla G\&R Fratelli, Bunge Europe, Campbell, Cargill, Kao Corporation, Kellog Europe, Kikkoman Foods Europe, Luigi Lavazza, Mondelez International, Mars, Nestlé, PepsiCo International, Premier Foods, Südzucker/BENEO Group, Unilever. The opinions expressed herein and the conclusions of this publication are those of the authors and do not necessarily represent the views of ILSI Europe nor those of its member companies.

Conflict of interest Academic members of this expert group received support from ILSI Europe the Process-related Compounds and Natural Toxins Task Force, consisting of reimbursement of travel costs and a small honorarium.

Open Access This article is distributed under the terms of the Creative Commons Attribution 4.0 International License (http:// creativecommons.org/licenses/by/4.0/), which permits unrestricted use, distribution, and reproduction in any medium, provided you give appropriate credit to the original author(s) and the source, provide a link to the Creative Commons license, and indicate if changes were made. 


\section{References}

Abalaka JA, Elegbede JA (1982) Aflatoxin distribution and total microbial counts in an edible oil extracting plant. Preliminary observations. Food Chem Toxicol 20:43-46

Abd Alla ES (1997) Zearalenone: incidence, toxigenic fungi and chemical decontamination in Egyptian cereals. Nahrung 41:362-365

Abrunhosa L, Paterson RRM, Venâncio A (2010) Biodegradation of ochratoxin a for food and feed decontamination. Toxins 2:1078-1099

Afolabi CG, Ojiambo PS, Ekpo EJA, Menkir M, Bandyopadhyay R (2007) Evaluation of maize inbred lines for resistance to Fusarium ear rot and fumonisin accumulation in grain in tropical Africa. Plant Dis 91:279-286

Afriyie-Gyawu E, Ankrah NA, Huebner HJ, Ofosuhene M, Kumi J, Johnson NM, Tang L, Xu L, Jolly PE, Ellis W, Ofori-Adjei D, Williams JH, Wang JS, Phillips TD (2008) NovaSil clay intervention in Ghanaians at high risk for aflatoxicosis. I. Study design and clinical outcomes. Food Addit Contam 25:76-87

Aiko V, Edamana P, Mehta A (2016) Decomposition and detoxification of aflatoxin B1 by lactic acid. J Sci Food Agric 96:1959-1966. doi:10.1002/jsfa.7304

Aiko V, Mehta A (2015) Occurrence, detection and detoxification of mycotoxins. J Biosci 40:943-954

Alberts JF, Engelbrecht Y, Steyn PS, Holzapfel W, van Zyl W (2006) Biological degradation of aflatoxin B-1 by Rhodococcus erythropolis cultures. International J Food Microbiol 109:121-126

Alberts JF, Gelderblom WCA, Botha A, van Zyl WH (2009) Degradation of aflatoxin B-1 by fungal laccase enzymes. Int J Food Microbiol $135: 47-52$

Alberts JF, van Zyl WH, Gelderblom WCA (2016) Biologically based methods for control of fumonisin-producing Fusarium species and reduction of the fumonisins. Front Microbiol 7:548. doi:10.3389 /fmicb.2016.00548

Alldrick AJ, Hajšelová M (2004) Zearalenone. In: Magan N, Olsen M (eds) Mycotoxins in food: detection and control, 1st edn. CRC Woodhead, Cambridge, pp. 353-362

Altug T, Youssef AE, Marth EH (1990) Degradation of aflatoxin B1 in dried figs by sodium bisulfite with or without heat, ultraviolet energy or hydrogen peroxide. J Food Prot 53:581-628

Aly SE (2002) Distribution of aflatoxins in product and by-products during glucose production from contaminated corn. Nahrung 46: 341-344

Amezqueta S, Gonzalez-Penas E, Murillo M, Lopez de Cerain A (2005) Occurrence of OTA in cocoa beans: effect of shelling. Food Addit Contam 22:590-596

Anese M, Suman M, Nicoli MC (2009) Technological strategies to reduce acrylamide levels in heated foods. Food Eng Rev 1:169-179

Applebaum RS, Marth HE (1982) Inactivation of aflatoxin M1 in milk using hydrogen peroxide and hydrogen peroxide plus riboflavin or lactoperoxidase. J Food Prot 45:557-560

Assatarakul K, Churey JJ, Manns DC, Worobo RW (2012) Patulin reduction in apple juice from concentrate by UV radiation and comparison of kinetic degradation models between apple juice and apple cider. J Food Prot 75:717-724

Aureli G, D’Egidio MG (2007) Efficacia della decorticazione nella riduzione del DON in frumento duro. Tecnica Molitoria 58:729-733

Bakiri I (2001) A study on the occurrence of aflatoxin M1 in milk and milk products produced in Van province of Turkey. Food Control 12:47-51

Basaran P, Basaran-Akgul N, Oksuz L (2008) Elimination of Aspergillus parasiticus from nut surface with low pressure cold plasma (LPCP) treatment. Food Microbiol 25:626-632

Bennett GA, Anderson RA (1978) Distribution of aflatoxin and/or zearalenone in wet-milled corn products: a review. J Agric Food Chem 26:1055-1060
Bennett GA, Peplinski AJ, Brekke OL, Jackson LK, Wichser WR (1976) Zearalenone - distribution in dry-milled fractions of contaminated corn. Cereal Chem 53:299-307

Bennett GA, Richard JL, Eckhoff SR (1996) Distribution of fumonisins in food and feed products prepared from contaminated corn. In: Jackson LS, DeVries JW, Bullerman LB (eds) Fumonisins in food. Plenum Press, New York, pp. 317-322

Bennett GA, Shotwell OL, Hesseltine CW (1980) Destruction of zearalenone in contaminated corn. J Am Oil Chem Soc 57:245-247

Bennett JW, Klich M (2003) Mycotoxins. Clin Microbiol Rev 16:497516

Berg T, Rasmussen G, Thorup I (1995) Mycotoxins in Danish foods. National Food Agency of Health, Soborg

Bergamini E, Catellani D, Dall'Asta C, Galaverna G, Dossena A, Marchelli R, Suman M (2010) Fate of Fusarium mycotoxins in the cereal product supply chain: the deoxynivalenol (DON) case within industrial bread-making technology. Food Addit Contam Part A Chem Anal Control Expo Risk Assess 27:677-687

Bfr, Bundesamt für Risikobewertung (2004) Mutterkornalkaloide in Roggenmehl. Stellungnahme des BfR vom 22. Januar 2004, http://www.bfr.bund.de/cm/343/mutterkornalkaloide_in roggenmehl.pdf. Accessed 16 July 2016

Biermaier B, Gottschalk C, Schwaiger K, Gareis M (2015) Occurrence of Stachybotrys chartarum chemotype S in dried culinary herbs. Mycotoxin Res 31:23-32

Binder J, Horvath EM, Schatzmayr G, Ellend N, Danner H, Krska R, Braun R (1997) Screening for deoxynivalenol-detoxifying anaerobic rumen microorganisms. Cereal Res Commun 25:343-346

Bindslev-Jensen C, Skov PS, Roggen EL, Hvass P, Brinch DS (2006) Investigation on possible allergenicity of 19 different commercial enzymes used in the food industry. Food Chem Toxicol 44:19091915

Bittner A, Cramer B, Harrer H, Humpf H-U (2015) Structure elucidation and in vitro cytotoxicity of ochratoxin alpha amide, a new degradation product of ochratoxin a. Mycotoxin Res 31:83-90

Blackwell BA, Gilliam JT, Savard ME, Miller D, Duvick JP (1999) Oxidative deamination of hydrolyzed fumonisin $\mathrm{B}(1)(\mathrm{AP}(1))$ by cultures of Exophiala spinifera. Nat Toxins 7:31-38

Blanc M, Pittet A, Munzobox R, Viani R (1998) Behaviour of ohratoxin a during green coffee roasting and soluble manufacture. J Agric Food Chem 46:673-675

Bordin K, Sawada MM, Rodrigues CEC, da Fonseca CR, Oliveira CAF (2014) Incidence of aflatoxins in oil seeds and possible transfer to oil: a review. Food Eng Rev 6:20-28

Böswald C, Engelhard G, Vogel H, Wallnöfer PR (1995) Metabolism of Fusarium mycotoxins zearalenone and deoxynivalenol by yeast strains of technological relevance. Nat Toxins 3:138-144

Bothast RJ, Bennett GA, Vancauwenberge JE, Richard JL (1992) Fate of fumonisin B1 in naturally contaminated corn during ethanol fermentation. Appl Environ Microbiol 58:233-236

Bothast RJ, Hesseltine CW (1975) Bright greenish-yellow fluorescence and aflatoxin in agricultural commodities. Appl Microbiol 30:337338

Boudra H, Bars PL, Bars JL (1995) Thermostability of Ochratoxin a in wheat under two moisture conditions. Appl Environ Microbiol 61: $1156-1158$

Brackett RE, Marth EH (1979) Stability of Patulin at pH 6.0-8.0 and $25^{\circ} \mathrm{C}$. Z Lebensm Unters Forsch 169:92-94

Brekke OL, Sinnhuder RO, Peplinski AJ, Wales JH, Putnam GB, Lee DJ, Ciegler A (1977) Aflatoxin in corn: ammonia inactivation and bioassay with rainbow trout. Appl Environ Microbiol 34:34-37

Brera C, Peduto A, Debegnach F, Pannunzi E, Prantera E, Gregori E, De Giacomo M, De Santis B (2013) Study of the influence of the milling process on the distribution of Deoxynivalenol content from the caryopsis to cooked pasta. Food Control 32:309 
Bretz M, Beyer M, Cramer B, Knecht A, Humpf H-U (2006) Thermal degradation of the Fusarium mycotoxin deoxynivalenol. J Agric Food Chem 54:6445-6451

Bretz M, Knecht A, Göckler S, Humpf H-U (2005) Structural elucidation and analysis of thermal degradation products of the Fusarium mycotoxin nivalenol. Mol Nutr Food Res 49:309-316

Bryła M, Roszko M, Szymczyk K, Jedrzejczak R, Slowik E, Obiedzinski MW (2014) Effect of baking on reduction of free and hidden fumonisins in gluten-free bread. J Agric Food Chem 62:1034110347

Bullerman LB, Bianchini A (2007) Stability of mycotoxins during food processing. Int J Food Microbiol 119:140-146

Bullerman LB, Schroeder LL, Park KY (1984) Formation and control of mycotoxins in food. J Food Prot 47:637-646

Canela R, Pujol R, Sala N, Sanchis V (1996) Fate of fumonisins B1 and B2 in steeped corn kernels. Food Addit Contam 13:511-517

Cano-Sancho G, Sanchis V, Ramos AJ, Marín S (2013) Effect of food processing on exposure assessment studies with mycotoxins. Food Addit Contam Part A 30:867-875

Castegnaro M, Friesa M, Michelon J, Walker EA (1981) Problems related to the use of sodium hypochlorite in the detoxification of aflatoxin B1. J Occup Environ Hygiene 42:398-401

Castoria R, Mannina L, Durán-Patrón R, Maffei F, Sobolev AP, De Felice DV, Pinedo-Rivilla C, Ritieni A, Ferracane R, Wright SAI (2011) Conversion of the mycotoxin patulin to the less toxic desoxypatulinic acid by the biocontrol yeast Rhodosporidium kratochvilovae strain LS11. J Agric Food Chem 59:11571-11578

Cazzaniga D, Basílico JC, González RJ, Torres RL, de Greef DM (2001) Mycotoxins inactivation by extrusion cooking of corn flour. Lett Appl Microbiol 33:144-147

Chakrabarti AG (1981) Detoxification of corn. J Food Prot 44:591-592

Cheftel JC (1989) Extrusion cooking and food safety. In: Mercier C, Linko P, Harper JM (eds) Extrusion cooking. American Association of Cereal Chemists, Minnesota, pp. 435-461

Cheli F, Pinotti L, Rossi L, Dell'Orto V (2013) Effect of milling procedures on mycotoxin distribution in wheat fractions: a review. LWTFood Science Technology 54:307-314

Chełkowski J, Goliński P, Godlewska B, Radomyska W, Szebiotko K, Wiewiórowska M (1981) Mycotoxins in cereal grain. Part IV. Inactivation of ochratoxin a and other mycotoxins during ammoniation. Nahrung 25:631-637

Choudhari AK, Kumari P (2010) Management of mycotoxin contamination in preharvest and postharvest crops: present status and future prospects. J Phytology 2:37-52

Ciegler A, Lillehoj EB, Peterson RE, Hall HH (1966) Microbial detoxification of aflatoxin. Appl Microbiol 14:934-939

Ciegler A, Peterson RE (1968) Aflatoxin detoxification: hydroxydihydroaflatoxin B1. Appl Microbiol 16:665-666

Codex Alimentarius (2015) General Standard for Food Additives (GSFA) Online Database. http://www.fao.org/fao-whocodexalimentarius/download/standards/4/CXS 192 2015e.pdf. Accessed 16 July 2016

Cole RJ, Dorner JW, Holbrook CC (1995) Separation and removal of aflatoxin contaminated kernels in peanut shelling plants. In: Stalker HT, Pattee HE (eds) Advances in peanut science, 1st edn. American Peanut Research and Education Society, Cornell, pp. 456-474

Collins GJ, Rosen JD (1981) Distribution of T-2 toxin in wet-milled corn products. J Food Sci 46:877-879

Conway HF, Anderson RA, Bagley EB (1978) Detoxification of aflatoxin-contaminated corn by roasting. Cereal Chem 55:115-117

Copetti MV, Iamanaka BT, Nester MA, Efraim P, Taniwaki MH (2013) Occurrence of OTA in cocoa by-products and determination of its reduction during chocolate manufacture. Food Chem 136:100-104
Copetti MV, Iamanaka BT, Pereira JL, Frisvad JC, Taniwaki MH (2011) Mycobiota of cocoa: from farm to chocolate. Food Microbiol 28: 1499-1504

Copetti MV, Iamanaka BT, Pereira JL, Frisvad JC, Taniwaki MH (2012) The effect of cocoa fermentation and weak organic acids on growth and OTA production by Aspergillus species. Int J Food Microbiol 155:158-164

Copetti MV, Iamanaka BT, Pitt JI, Taniwaki MH (2014) Fungi and mycotoxins in cocoa: from farm to chocolate. Int J Food Microbiol 178: $13-20$

Cozzini P, Dellafiora L (2012) In silico approach to evaluate molecular interaction between mycotoxins and the estrogen receptors ligand binding domain: a case study on zearalenone and its metabolites. Toxicol Lett 214:81-85

Cramer B, Königs M, Humpf H-U (2008) Identification and in vitro cytotoxicity of ochratoxin a degradation products formed during coffee roasting. J Agric Food Chem 56:5673-5681

Cucullu AF, Lee LS, Pons WA, Stanley JB (1976) Ammoniation of aflatoxin B1: isolation and characterization of a product with molecular weight 206. J Agric Food Chem 24:408-410

Dall'Asta C, Scarlato AP, Galaverna G, Brighenti F, Pellegrini N (2012) Dietary exposure to fumonisins and evaluation of nutrient intake in a group of adult celiac patients on a gluten-free diet. Mol Nutr Food Res 56:632-640

Dam R, Tam SW, Satterlee LD (1977) Destruction of aflatoxins during fermentation and by-product isolation from artificially contaminated grain. Cereal Chem 54:705-714

Dänicke S, Kersten S, Valenta H, Breves G (2012) Inactivation of deoxynivalenol-contaminated cereal grains with sodium metabisulfite: a review of procedures and toxicological aspects. Mycotoxin Res 28:199-218

Dänicke S, Valenta H, Gareis M, Lucht HW, von Reichenbach H (2005) On the effects of a hydrothermal treatment of deoxynivalenol (DON)-contaminated wheat in the presence of sodium metabisulphite (Na2S2O5) on DON reduction and on piglet performance. Anim Feed Sci Technol 118:93-108

Dano SD, Manda P, Dembélé A, Kouassi Abla AM, Bibaud JH, Gouet JZ, Bruno C, Sika CMZM (2013) Influence of fermentation and drying materials on the contamination of cocoa beans by ochratoxin a. Toxins 5:2310-2323

Davidson JI Jr, Holaday CE, Bennett CT (1981) Separation and removal of aflatoxin contaminated kernels in peanut shelling plants. Proc Am Peanut Res Edu Soc 13:29-45

de Nijs M, van Egmond HP, Nauta M, Rombouts FM, Notermans S (2012) Mycotoxin binders in feed: food safety aspects. In report 2011.019 of RIKILT, Institute of Food Safety. Wageningen University (University\& Research Centre), Wageningen

Dobritzsch D, Wang H, Schneider G, Yu S (2014) Structural and functional characterization of ochratoxinase, a novel mycotoxindegrading enzyme. Biochem J 462:441-452

Dombrink-Kurtzman MA, Dvorak TJ, Barron ME, Rooney LW (2000) Effect of nixtamalization (alkaline cooking) on fumonisincontaminated corn for production of masa and tortillias. J Agric Food Chem 48:5781-5786

Dorner JW (2008) Management and prevention of mycotoxins in peanuts. Food Add Contam 25:203-208

Doster MA, Michailides TJ (1998) Production of bright greenish yellow fluorescence in figs infected by Aspergillus species in California orchards. Plant Dis 82:669-673

Doyle MP, Applebaum RS, Brackett RE, Marth EH (1982) Physical, chemical and biological degradation of mycotoxins in foods and agricultural commodities. J Food Prot 45:964-971

Doyle MP, Marth EH (1978a) Bisulfite degrades aflatoxin: effect of temperature and concentration of bisulfite. J Food Prot 41:774-780 
Doyle MP, Marth EH (1978b) Bisulfite degrades aflatoxin: effect of citric acid and methanol and possible mechanism of degradation. J Food Prot 41:891-896

Draughon FA, Childs EA (1982) Chemical and biological evaluation of aflatoxin after treatment with sodium hypochlorite, sodium hydroxide and ammonium hydroxide. J Food Prot 45: 703-706

Drusch S, Ragab W (2003) Mycotoxins in fruits, fruit juices, and dried fruits. J Food Prot 66:1514-1527

Durmus E, Kalkan H (2016) Detection of aflatoxin and surface mould contaminated figs by using Fourier-transform near-infrared (FTNIR) reflectance spectroscopy. J Agric Food Chem. doi:10.1002 /jsfa. 7735

Dusemund B, Altman HJ, Lampen A (2006) II. Toxicologischer Bewertung Mutterkornalkaloid-kontaminierter Roggenmehle. J Consum Prot Food Safety 1:150-152

Dutton MF, Heathcote JG (1968) The structure, biochemical properties and origin of aflatoxins B2a and G2a. Chem Ind 13:418-421

Duvick J (2001) Prospects for reducing fumonisin contamination of maize through genetic modification. Environ Health Perspect 109: 337-342

Dwarakanath CT, Rayner ET, Mann GE, Dollear FG (1968) Reduction of aflatoxin levels in cottonseed and peanut meals by ozonization. J Am Oil Chem Soc 45:93

EC, European Commission (2006) Regulation no 1881/2006 of 19 December 2006 setting maximum levels for certain contaminants in foodstuffs. Off J Eur U L 364:5

EC, European Commission (2013) Aflatoxin contamination in hazelnuts and dried figs intended for export to the EU, http://ec.europa. $\mathrm{eu} / \mathrm{food} / \mathrm{fvo} /$ act getPDF.cfm?PDF ID=10210

EC, European Commission (2015) Regulation 2015/786 defining acceptability criteria for detoxification processes applied to products intended for animal feed. Off J Eur Union 125:10-14

Edwards SG (2004) Influence of agricultural practices on Fusarium infection of cereals and subsequent contamination of grain by trichothecene mycotoxins. Toxicol Lett 153:29-36

EFSA, European Food Safety Authory (2009) Guidance on the submission of a Dossier on food enzymes for safety evaluation by the scientific panel of food contact material, enzymes, flavourings and processing aids. EFSA J 1305:1-26

EFSA, European Food Safety Authority Panel on Contaminants in the Food Chain (CONTAM) (2004) EFSA scientific opinion on deoxynivalenol (DON) as undesirable substance in animal feed. EFSA J 73:1-42

EFSA, European Food Safety Authority Panel on Contaminants in the Food Chain (CONTAM) (2005) EFSA scientific opinion on fumonisins as undesirable substances in animal feed. EFSA J 235: $1-32$

EFSA, European Food Safety Authority Panel on Contaminants in the Food Chain (CONTAM) (2006) EFSA scientific opinion on ochratoxin a in food. EFSA J 365:1-56

EFSA, European Food Safety Authority Panel on Contaminants in the Food Chain (CONTAM) (2007) European food safety authority (EFSA) scientific opinion related to the potential increase of consumer health risk by a possible increase of the existing maximum levels for aflatoxins in almonds, hazelnuts and pistachios and derived products. EFSA J 446:1-127

EFSA, European Food Safety Authority Panel on Contaminants in the Food Chain (CONTAM) (2011a) EFSA scientific opinion on the risks for animal and public health related to the presence of T-2 and HT-2 toxin in food and feed. EFSA J 9:2481

EFSA, European Food Safety Authority Panel on Contaminants in the Food Chain (CONTAM) (2011b) EFSA scientific opinion on the risks for public health related to the presence of zearalenone in food. EFSA J 9:2197
EFSA, European Food Safety Authority Panel on Contaminants in the Food Chain (CONTAM) (2012) EFSA scientific opinion on ergot alkaloids in food and feed. EFSA J 10:2798

EFSA, European Food Safety Authority Panel on Contaminants in the Food Chain (CONTAM) (2013) Scientific opinion on the risks for animal and public health related to the presence of nivalenol in food and feed. EFSA J 11:3262

EFSA, European Food Safety Authority Panel on Contaminants in the Food Chain (CONTAM) (2014) EFSA scientific opinion on the risks for human and animal health related to the presence of modified forms of certain mycotoxins in food and feed. EFSA J 12:3916

FAO/WHO (2003) Codex Alimentarius: CAC/RCP 50 - Code of practice for the prevention and reduction of patulin contamination in apple juice and apple juice ingredients in other beverages. Food and Agriculture Organization. http://www.fao.org/input/download/standards/405 /CXP 050e.pdf. Accessed 19 May 2016

Fernandez-Surumay G, Osweiler GD, Yaeger MJ, Rottinghaus GE, Hendrich S, Buckley LK, Murphy PA (2005) Fumonisin Bglucose reaction products are less toxic when fed to swine. J Agric Food Chem 53:4264-4271

Fliege R, Metzler M (1999) The mycotoxin patulin induces intra-and intermolecular patulin cross-links in vitro involving cysteine, lysine and histidine side chains and alfa-amino groups. Chem-Biol Interactions 123:85-103

Fouler SG, Trivedi AB, Kitabatake N (1994) Detoxification of citrinin and ochratoxin a by hydrogen peroxide. J Assoc Off Agric Chem Int 77:631-637

Fraenkel H (1962) Colour sorting machine. US Patent No. 3,066,797

Generotti S, Cirlini M, Dall'Asta C, Suman M (2015b) Influence of the industrial process from caryopsis to cornmeal semolina on levels of fumonisins and their masked forms. Food Control 48:170-174

Generotti S, Cirlini M, Malachova A, Sulyok M, Berthiller F, Dall'Asta C, Suman M (2015a) Deoxynivalenol and deoxynivalenol-3glucoside mitigation through bakery production strategies: effective experimental design within industrial rusk-making technology. Toxins 7:2773-2790

Ghanem I, Orfi M, Shamma M (2008) Effect of gamma radiation on the inactivation of aflatoxin B1 in food and feed crops. Braz J Microbiol 39:787-791

Gilmour M, Lindblom M (2008) Management of OTA in the cocoa supply chain: a summary of work by the CAOBISCO/ECA/FCC working group on OTA. In: Leslie JF, Bandyopadhyay R, Visconti A (eds) Mycotoxins: detection methods, management, Public Health and Agricultural Trade. CABI, Wallingford, pp. 231-243

Govaris A, Roussi V, Koidis PA, Botsoglou NAA (2001) Distribution and stability of aflatoxin M1 during processing, ripening, and storage of Telemes cheese. Food Addit Contam 18:437-443

Govaris A, Roussi V, Koidis PA, Botsoglou NAA (2002) Distribution and stability of aflatoxin M1 during production and storage of yoghurt. Food Addit Contam 19:1043-1050

Grenier B, Bracarense AP, Leslie JF, Oswald IP (2014) Physical and chemical methods for mycotoxin decontamination in maize. In: Leslie JF, Logrieco AF (eds) Mycotoxin reduction in grain chains. Wiley Blackwell, New Delhi, pp. 116-129

Grenier B, Bracarense A-PFL, Schwartz HE, Trumel C, Cossalter A-M, Schatzmayr G, Kolf-Clauw M, Moll W-D, Oswald IP (2012) The low intestinal and hepatic toxicity of hydrolyzed fumonisin $\mathrm{B}_{1}$ correlates with its inability to alter the metabolism of sphingolipids. Biochem Pharmacol 83:1465-1473

Hackbart HCS, Machado AR, Christ-Ribeiro A, Prietto L, BadialeFurlong E (2014) Reduction of aflatoxins by Rhizopus oryzae and Trichoderma Reesei. Mycotoxin Res 30:141-149

Hagler WM, Winston M, Hutchins JE, Hamilton PB (1982) Destruction of Aflatoxin in corn with sodium bisulfite. J Food Prot 45:1287-1291

Hahn I, Nagl V, Schwartz-Zimmermann HE, Varga E, Schwarz C, Slavik V, Reisinger N, Malachová A, Cirlini M, Generotti S, Dall'Asta C, 
Krska R, Moll WD, Berthiller F (2015) Effects of orally administered fumonisin $\mathrm{B}_{1}\left(\mathrm{FB}_{1}\right)$, partially hydrolysed $\mathrm{FB}_{1}$, hydrolysed $\mathrm{FB}_{1}$ and $\mathrm{N}$-(1-deoxy-D-fructos-1-yl) $\mathrm{FB}_{1}$ on the sphingolipid metabolism in rats. Food Chem Toxicol 76:11-18

Haskard C, El-Nezami GS, Kankaanpää PE, Salminen S, Ahokas JT (2001) Surface binding of aflatoxin B1 by lactic acid bacteria. Appl Environ Microbiol 67:3086-3091

Hathout AS, Aly SE (2014) Biological detoxification of mycotoxins: a review. Ann Microbiol 64:905-919

He JW, Bondy GS, Zhou T, et al. (2015) Toxicology of 3-epideoxynivalenol, a deoxynivalenol-transformation product by Devosia mutans 17-2-E-8. Food Chem Toxicol 84:250-259

He JW, Hassan YI, Perilla N, Li XZ, Boland GJ, Zhou T (2016) Bacterial epimerization as a route for deoxynivalenol detoxification: the influence of growth and environmental conditions. Front Microbiol. doi:10.3389/fmicb.2016.00572

He J, Zhou T (2010) Patented techniques for detoxification of mycotoxins in feeds and food matrices. Recent Pat Food Nutr Agric 2:96-104

He J, Zhou T, Young JC, Boland GJ, Scott PA (2010) Chemical and biological transformations for detoxification of trichothecene mycotoxins in human and animal food chains: a review. Trends Food Sci Technol 21:67-76

Heinl S, Hartinger D, Thamhesl M, Vekiru E, Krska R, Schatzmayr G, Moll W-D, Grabherr R (2010) Degradation of fumonisin $B_{1}$ by the consecutive action of two bacterial enzymes. J Biotechnol 145:120 129

Herzallah S, Al Shawabkeh K, Al Fataftah A (2008) Aflatoxin decontamination of artificially contaminated feeds by sunlight, g-radiation, and microwave heating. J Appl Poult Res 17:515-521

Holzapfel CW, Steyn PS, Purchase IFH (1966) Isolation and structure of aflatoxins M1 and M2. Tetrahedron Lett 7:2799-2803. doi:10.1016 /S0040-4039(01)99863-6

Hong S-J, Lee Y-H, Khan AR, Ullah I, Lee C, Park CK, Shin J-H (2014) Cloning, expression, and characterization of thermophilic Lasparaginase from Thermococcus kodakarensis KOD1. J Basic Microbiol 54:500-508

Hormisch D, Brost I, Kohring GW, Giffhorn E, Kroppenstedt RM, Stackebrandt E, Färber P, Holzapfel WH (2004) Mycobacterium fluoranthenivorans sp nov., a fluoranthene and aflatoxin B-1 degrading bacterium from contaminated soil of a former coal gas plant. Syst Appl Microbiol 27:653-660

Huff WE (1980) A physical method for the segregation of aflatoxincontaminated corn. Cereal Chem 57:236-238

Huff WE, Hagler WM (1985) Density segregation of corn and wheat naturally contaminated with aflatoxin, deoxynivalenol and zearalenone. J Food Prot 48:416-420

Humpf H-U, Schmelz EM, Meredith FI, Vesper H, Vales TR, Wang E, Menaldino DS, Liotta DC, Merrill AH (1998) Acylation of naturally occurring and synthetic 1deoxysphinganines by ceramide synthase-formation of $\mathrm{N}$ palmitoyl-aminopentol produces a toxic metabolite of hydrolyzed fumonisin, AP(1), and a new category of ceramide synthase inhibitor. J Biol Chem 273:19060-19064

IARC, International Agency for Research on Cancer (1986) Monographs on the evaluation of carcinogenic risk of chemicals to humans. Volume 40: Some naturally occurring and synthetic food components, furocoumarins and ultraviolet radiation

IARC, International Agency for Research on Cancer (1993) Monographs on the evaluation of carcinogenic risks to humans volume 56. Some naturally occurring substances: Food items and constituents, heterocyclic aromatic amines and mycotoxins

IARC, International Agency for Research on Cancer (2002) Monographs on the evaluation of carcinogenic risks to humans volume 82: Some traditional herbal medicines, some mycotoxins, naphthalene and styrene. International Agency for Research on Cancer.
IARC, International Agency for Research on Cancer (2012) Monographs on the evaluation of carcinogenic risks to humans volume 100F: chemical agents and related occupations

Ikunaga Y, Sato I, Grond S, Numaziri N, Yoshida S, Yamaya H, Hiradate S, Hasegawa M, Toshima H, Koitabashi M, Ito M, Karlovsky P, Tsushima S (2011) Nocardioides sp. strain WSN05-2, isolated from a wheat field, degrades deoxynivalenol, producing the novel intermediate 3-epi-deoxynivalenol. Appl Microbiol Biotechnol 89:419 427

Inan F, Pala M, Doymaz I (2007) Use of ozone in detoxification of aflatoxin $B_{1}$ in red pepper. J Stored Prod Res 43:425-429

Inoue T, Nagatomi Y, Uyama A, Mochizuki N (2013) Fate of mycotoxins during beer brewing and fermentation. Biosci Biotechnol Biochem $77: 1410-1415$

Isaacson C (2005) The change of the staple diet of black south Africans from sorghum to maize (corn) is the cause of the epidemic of squamous carcinoma of the oesophagus. Med Hypotheses 64:658-660

Ishikawa I, Ueno Y, Tsunoda H (1970) Chemical determination of the chlorine-containing peptide, a hepatotoxic mycotoxin of Penicillium islandicum Sopp. J Biochem 67:753-758

Ito M, Sato I, Ishizaka M, Yoshida S, Koitabashi M, Yoshida S, Tsushima S (2013) Bacterial cytochrome P450 system catabolizing the Fusarium toxin deoxynivalenol. Appl Environ Microbiol 79: $1619-1628$

Itoh Y, Morishita Y, Aibara K (1980) Modification of aflatoxin $B_{1}$ in alkaline solutions. Nippon Nogeikagaku Kaishi 54:527-534

Jacobsen BJ (2014) Good agricultural and harvest practices to reduce mycotoxin contamination in wheat in temperate countries. In: Leslie JF, Logrieco AF (eds) Mycotoxin reduction in grain chains. Wiley Blackwell, New Delhi, pp. 209-219

Jalili M, Jinap S, Noranizan MA (2012) Aflatoxins and ochratoxin a reduction in black and white pepper by gamma radiation. Rad Phys Chem 81:1786-1788

Jans D, Pedrosa K, Schatzmayr D, Bertin G, Grenier B (2014) Mycotoxin reduction in animal diets. In: Leslie JF, Logrieco AF (eds) Mycotoxin reduction in grain chains. Wiley, Oxford, pp. 101-110. doi:10.1002/9781118832790

JECFA, Joint FAO/WHO Expert Committee on Food Additives (1996) Evaluation of certain veterinary drug residues in food, Prepared by the 45th JECFA meeting Additives. WHO Technical Report Series, No. 864

JECFA, Joint FAO/WHO Expert Committee on Food Additives (1999) Safety evaluation of certain food additives and contaminants, Prepared by the 49th JECFA meeting. WHO Technical Report Series, No. 884

JECFA, Joint FAO/WHO Expert Committee on Food Additives (2000) Safety evaluation of certain food additives and contaminants, Prepared by the 51st JECFA meeting. WHO Technical Report Series, No. 891

JECFA, Joint FAO/WHO Expert Committee on Food Additives (2001a) Safety evaluation of certain food additives and contaminants, Prepared by the 55th JECFA meeting. WHO Technical Report Series, No. 901

JECFA, Joint FAO/WHO Expert Committee on Food Additives (2001b) General specifications and considerations for enzyme preparations. Prepared by the 57th JECFA meeting

JECFA, Joint FAO/WHO Expert Committee on Food Additives (2011) Safety evaluation of certain food additives and contaminants, Prepared by the 74th JECFA meeting, WHO Technical Report Series, No. 966

JECFA, Joint FAO/WHO Expert Committee on Food Additives (2012) Safety evaluation of certain food additives and contaminants, Prepared by the 76th JECFA meeting, WHO Technical Report Series, No. 974 
Johansson AS, Whitaker TB, Hagler WM Jr, Bowman DT, Slate AB, Payne G (2006) Predicting aflatoxin and fumonisin in shelled corn lots using poor-quality grade components. J AOAC Int 89:433-440

Kabak B, Dobson AD, Var I (2006) Strategies to prevent mycotoxin contamination of food and animal feed: a review. Crit Rev Food Sci Nutr 46:593-619

Kamimura LM, Nishijima M, Tabata S, Yasuda K, Ushiyama H, Nishima JJ (1986) Survey of mycotoxin contamination on edible oil and fate on mycotoxin during oil-refining processes. Food Hygiene Soc Japan 27:59-63

Karlovsky P (1999) Biological detoxification of fungal toxins and its use in plant breeding, feed and food production. Nat Toxins 7:1-23

Karlovsky P (2011) Biological detoxification of the mycotoxin deoxynivalenol and its use in genetically engineered crops and feed additives. Appl Microbiol Biotechnol 91:491-504

Karlovsky P (2014) Enzymatic detoxification of mycotoxins for healthy food. New Food 17:66-69

Karlovsky P (2016) Detoxification strategies for mycotoxins in plant breeding. In: Dall'Asta C, Berthiller F (eds) Masked mycotoxins in food: formation, occurrence and toxicological relevance. Royal Society of Chemistry, Cambridge, pp. 158-188

Karlovsky P, Crane E III, Gilliam JT, Maddox JR (2003) Compositions and methods of zearalenone detoxification. US patent No. 20030073239, pp 1-30

Kaushik G (2015) Effect of processing on mycotoxin content in grains. Crit Rev Food Sci Nutr 55:1672-1683

Kavlock R, Chandler K, Houck K, Hunter S, Judson R, Kleinstreuer N, Knudsen T, Martin M, Padilla S, Reif D, Richard A, Rotroff D, Sipes N, Richard A (2012) Update on EPA's ToxCast program: providing high throughput decision support tools for chemical risk assessment. Chem Res Toxicol 25:1287-1302

Kiermeier F, Ruffer L (1974) Veranderung von Aflatoxin $B_{1}$ in alkalischer Losung. Z Lebensm Unters Forsch 155:129-141

Kilonzo RM, Imungi JK, Muiru WM, Lamuka PO, Njage PM (2014) Household dietary exposure to aflatoxins from maize and maize products in Kenya. Food Addit Contam Part A 31:2055-2062

Köppen R, Riedel J, Proske M, Drzymala S, Rasenko T, Durmaz V, Weber M, Koch M (2012) Photochemical trans-/cis-isomerization and quantitation of zearalenone in edible oils. J Agric Food Chem 60:11733-11740

Kostelanska M, Dzuman Z, Malachova A, Capouchova I, Prokinova E, Skerikova A, Hajslova J (2011) Effects of milling and baking technologies on levels of deoxynivalenol and its masked form deoxynivalenol-3-glucoside. J Agric Food Chem 59:9303-9312

Lancova K, Hajslova J, Kostelanska M, Kohoutkova J, Nedelnik J, Moravcova H, Vanova M (2008a) Fate of trichothecene mycotoxins during the processing: milling and baking. Food Addit Contam Part A 25:650-659

Lancova K, Hajslova J, Poustka J, Krplova A, Zachariasova M, Dostalek P, Sachambula L (2008b) Transfer of fusarium mycotoxins and "masked" deoxynivalenol (deoxynivalenol-3-glucoside) from field barley through malt to beer. Food Addit Contam Part A Chem Anal Control Expo Risk Assess 25:732-744

Lasztity R, Tamás K, Wöller L (1977) Occurrence of Fusarium mycotoxins in some Hungarian corn crops and the possibilities of detoxification. Annales de la Nutrition et de l'Alimentation 31:495-498

Lefyedi ML, Taylor JRN (2006) Effect of dilute alkaline steeping on the microbial contamination, toxicity and diastatic power of sorghum malt. J Inst Brew 112:108-116

Leggett NL, Shephard GS, Stockenström S, Staal E, van Schatwijk DJ (2001) The reduction of patulin in apple juices by the three different types of activated carbon. Food Addit Contam 18:825-829

Leoni LA, Soares LM, Oliveira PL (2000) Ochratoxin a in Brazilian roasted and instant coffees. Food Addit Contam 17:867-870

Maeba H, Takamoto Y, Kamimura MI, Miura TO (1988) Destruction and detoxification of aflatoxins with ozone. J Food Sci 53:667-668
Magan N, Aldred D (2005) Conditions of formation of OTA in drying, transport and in different commodities. Food Addit Contam 1:10-16

Mahoney N, Molyneux RJ (2010) Rapid analytical method for the determination of aflatoxins in plant-derived dietary supplement and cosmetic oils. J Agric Food Chem 58:4065-4070

Manda P, Dano DS, Kouadio JH, Diakite A, Sangare-Tigori B, Ezoulin MJM, Soumahoro A, Dembele A, Fourny G (2009) Impact of industrial treatments on ochratoxin a content in artificially contaminated cocoa beans. Food Addit Contam Part A 26:1081-1088

Masloff S (2006) Mutterkornalkaloide in Lebensmitteln. J Verbr Lebensm 1:153-154

Masri MS, Vix HLE, Goldblatt LA (1969) Process for de-toxifying substances contaminated with aflatoxin. United States Patent No. 3.429.709

Matsuura Y, Yoshizawa T (1985) Conversion of zearalenone, an estrogenic mycotoxin, by brewing microorganisms. J Food Hyg Soc Japan 26:24-28

Matsuura Y, Yoshizawa T, Morooka N (1979) Stability of zearalenone in aqueous solutions of some food additives. J Food Hyg Soc Japan 20: 385-390

Mayer J (1898) Grain-sorting machine. United States Patent No. 671,500

McCormick SP (2013) Microbial detoxification of mycotoxins. J Chem Ecol 39:907-918

McKenzie KS, Sarr AB, Mayura K, Bailey RH, Miller DR, Rogers TD, Norred WP, Voss KA, Plattner RD, Kubena LF, Phillips TD (1997) Oxidative degradation and detoxification of mycotoxins using a novel source of ozone. Food Chem Toxicol 35:807-820

Meca G, Ritieni A, Mañes J (2012) Influence of the heat treatment on the degradation of the minor Fusarium mycotoxin beauvericin. Food Control 28:13-18

Megalla SE, Mohran MA (1984) Fate of aflatoxin B-1 in fermented dairy products. Mycopathologia 88:27-29

Mendez-Albores A, Campos-Agular AZ, Moreno-Martinez E, VazquezDuran A (2013) Physical and chemical degradation of B-aflatoxins during the roasting and dutching of cocoa liquor. J Agr Sci Tech 15: 557-567

Merkel S, Dib B, Maul R, Köpper R, Koch M, Dehls I (2012) Degradation and epimerization of ergot alkaloids after baking and in vitro digestion. Anal Bioanal Chem 404:2489-2497

Mesterhazy A (2014) Breeding for resistance to Fusarium head blight in wheat. In: Leslie JF, Logrieco AF (eds) Mycotoxin reduction in grain chains. Wiley Blackwell, New Delhi, pp. 189-208

Miedaner T, Geiger HH (2015) Biology, genetics, and management of ergot (Claviceps spp.) in rye, sorghum, and pearl millet. Toxins 7: 659-678

Milanez MFFL (1996) The effect of cooking on ochratoxin a content of beans, variety carioca. Food Addit Contam 13:89-93

Milani J, Maleki G (2014) Effects of processing on mycotoxin stability in cereals. J Food Sci and Agric 94:2372-2375

Moerck KE, McElfresh P, Wohlman A, Hilton B (1980) Aflatoxin destruction in corn using sodium bisulfite, sodium hydroxide and aqueous ammonia. J Food Prot 43:571-574

Monaci L, De Angelis E, Visconti AJ (2011) Determination of deoxynivalenol, T-2 and HT-2 toxins in a bread model food by liquid chromatography-high resolution-Orbitrap-mass spectrometry equipped with a high-energy collision dissociation cell. Chromatogr A 1218:8646-8654

Moss MO (1971) The rubratoxins, toxic metabolites of Penicillium rubrum Stoll. In: Ciegler A, Kadis S, Ayl SJ (eds) Mycrobial toxins 6. Academic, London, pp. 381-497

Moss MO, Long MT (2002) Fate of patulin in the presence of the yeast Saccharomyces cerevisiae. Food Add Contam 19:387-399

Mounjouenpou P, Mbang JA, Guyot B, Guiraud JP (2012) Traditional procedures of cocoa processing and occurrence of ochratoxin-a in the derived products. J Chem Pharm Res 4:1332-1339 
Müller HM (1983) Entgiftung von Mykotoxinen: II. Chemische Verfahren und Reaktion mit Inhaltsstoffen von Futtermitteln. Übers Tierernährg 11:47-80

Munkvold GP (2014) Crop management practices to minimize the risk of mycotoxins contamination in temperate-zone maize. In: Leslie JF, Logrieco AF (eds) Mycotoxin reduction in grain chains. Wiley Blackwell, New Delhi, pp. 59-77

Munkvold GP, Desjardins AE (1988) Fumonisins in maize: can we reduce their occurrence? Plant Dis 81:556-565

Murphy PA, Rice LG, Ross PF (1993) Fumonisin- $B_{1}$, fumonisin $B_{2}$, and fumonisin $\mathrm{B}_{3}$ content of Iowa, Wisconsin, and Illinois corn and corn screenings. J Agric Food Chem 41:263-266

Muthaiyan MC (2009) Plant quarantine treatments. In: Muthaiyan MC (ed) Principles and practices of plant quarantine. Allied Publishers, New Delhi, pp. 650-739

Mutiga SK, Were V, Hoffmann V, Harvey HW, Milgroom MG, Nelson RJ (2014) Extent and drivers of mycotoxin contamination: inferences from a survey of Kenyan maize mills. Phytopathology 104: 1221-1231. doi:10.1094/PHYTO-01-14-0006-R

Mutungi C, Lamuka P, Arimi S, Gathumbi J, Onyango C (2008) The fate of aflatoxins during processing of maize into muthokoi-a traditional Kenyan food. Food Control 19:714-721

Nakazato M, Morozumi S, Saito K, Fujinuma K, Nishima T, Kasai N (1990) Interconversion of aflatoxin B1 and aflatoxicol by several fungi. Appl Environ Microbiol 56:1465-1470

Natarajan KR, Rhee KC, Cater CM, Mattil KF (1974) Destruction of aflatoxins in peanut protein isolates by sodium hypochlorite. $\mathrm{J}$ Am Oil Chem Soc 52:160-163

Norred WP, Voss KA, Bacon CW, Riley RT (1991) Effectiveness of ammonia treatment in detoxification of fumonisin-contaminated corn. Food Chem Toxicol 29:815-819

NTP, US National Toxicology Program (2000) NTP technical report on the toxicology and carcinogenesis studies of fumonisin B1 (CAS No 116355-83-0) in F344/N Rats and B6C3F1 Mice (Feed Studies) (TR 496; NIH Publication No 99-3955). Research Triangle Park, NC

Numanoglu E, Uygun U, Koksel H, Solfrizzo M (2010) Stability of Fusarium toxins during traditional Turkish maize bread production. Qual Assur Saf Crop 2:84-92

Numanoglu E, Yener S, Gökmen V, Uygun U, Koksel H (2013) Modelling thermal degradation of zearalenone in maize bread during baking. Food Addit Contam Part A 30:528-533

O'Neill K, Damoglou AP, Patterson MF (1993) The stability of deoxynivalenol and 3-acetyl deoxynivalenol to gamma irradiation. Food Addit Contam 10:209-215

Okonko PO, Nwokolo C (1978) Aflatoxin $B_{1}$ : simple procedures to reduce levels in tropical foods. Nutr Rep Int 17:387-395

Oliveira G, da Silva DM, Pereira RGFA, Paiva LC, Prado G, Batista LR (2013) Effect of different roasting levels and particle sizes on ochratoxin a concentration in coffee beans. Food Control 34:651-656

Ouf SA, Basher AH, Mohamed AA (2015) Inhibitory effect of double atmospheric pressure argon cold plasma on spores and mycotoxin production of Aspergillus niger contaminating date palm fruits. J Sci Food Agric 95:3204-3210

Ozay G, Aran N, Pala M (1995) Influence of harvesting and drying techniques on micoflora and mycotoxin contamination of figs. Nahrung 2:156-165

Panda P, Mehta A (2013) Aflatoxin detoxification potential of Ocimum tenuiflorum. J Food Safety 33:265-272

Park DL, Lee LS, Price RL, Pohland AE (1988) Review of the decontamination of aflatoxins by ammoniation: current status and regulation. J Assoc Off Anal Chem 71:685-703

Park DL, López-García R, Trujillo-Preciado S, Price RL (1996) Reduction of risks associated with fumonisin contamination in corn. Adv Exp Med Biol 392:335-344
Park DL, Rua SM, Mirocha CJ, Abd-alla E, Weng CJ (1992) Mutagenic potentials of fumonisin contaminated corn following ammonia decontamination procedure. Mycopathologia 117:105-108

Park JW, Kim YB (2006) Effect of pressure cooking on aflatoxin $B_{1}$ in rice. J Agric Food Chem 54:2431-2435

Parker WA, Melnick D (1966) Absence of aflatoxin from refined vegetable oils. J Am Oil Chem Soc 43:635-638

Pearson TC, Wicklow DT, Pasikatan MC (2004) Reduction of aflatoxin and fumonisin contamination in yellow corn by high-speed dualwavelength sorting. Cereal Chem 81:490-498

Petruzzi L, Bevilacqua A, Baiano A, Beneduce L, Corbo MR, Sinigaglia $M$ (2014) In vitro removal of ochratoxin a by two strains of Saccharomyces cerevisiae and their performances under fermentative and stressing conditions. J Appl Microbiol 116:60-70

Pierides M, El-Nezami H, Peltonen K, Salminen S, Ahokas J (2000) Ability of dairy strains of lactic acid bacteria to bind aflatoxin M1 in a food model. J Food Prot 63:645-650

Pietri A, Zanetti M, Bertuzzi T (2009) Distribution of aflatoxins and fumonisins in dry-milled maize fractions. Food Addit Contam Part A-Chem 26:372-380

Pitout MJ (1969) The hydrolysis of ochratoxin a by some proteolytic enzymes. Biochem Pharmacol 18:485-491

Plante EC, Sutherland KL (1944) The physical chemistry of flotation. X. The separation of ergot from rye. J Phys Chem 48:203-223. doi:10.1021/j150436a008

Popiel D, Koczyk G, Dawidziuk A, Gromadzka K, Blaszczyk L, Chelkowski J (2014) Zearalenone lactonohydrolase activity in Hypocreales and its evolutionary relationships within the epoxide hydrolase subset of a/b-hydrolases. BMC Microbiol 14:82

Proctor AD, Ahmedna M, Kumar JV, Goktepe I (2004) Degradation of aflatoxins in peanut kernels/flour by gaseous ozonation and mild heat treatment. Food Addit Contam 21:786-793

Pujol R, Torres M, Sanchis V, Canela R (1999) Fate of fumonisin $B_{1}$ in corn kernel steeping water containing $\mathrm{SO}_{2}$. J Agric Food Chem 47: 276-278

Rastegar H, Shoeibi S, Yazdanpanah H, Amirahmadi M, Khaneghah AM, Campagnollo FB, Sant'Ana A (2016) Removal of aflatoxin B1 by roasting with lemon juice and/or citric acid in contaminated pistachio nuts. Food Control 71:279-284

Raters M, Matissek R (2008) Thermal stability of aflatoxin B1 and ochratoxin a. Mycotoxin Res 24:130-134. doi:10.1007/BF03032339

Rogers KD, Cannistra JC, Gloer JB, Wicklow DT (2014) Diplodiatoxin, chaetoglobosins, and diplonine associated with a field outbreak of Stenocarpella ear rot in Illinois. Mycotoxin Res 30:61-70

Rogers TD, Hitchens GD, Salinas CE, Murphy OG, Whitford HW (1992) Water purification, microbiological control, sterilization and organic waste decomposition using an electrochemical advanced ozonation process. SAE Technical Paper No. 921234. doi: 10.4271/921234

Rotter RG, Rotter BA, Thompson BK, Prelusky DB, Trenholm HL (1995) Effectiveness of density segregation and sodium carbonate treatment on the detoxification of Fusarium-contaminated corn fed to growing pigs. J Sci Food Agric 68:331-336

Rychlik M, Humpf H-U, Marko D, Dänicke S, Mally A, Berthiller F, Klaffke H, Lorenz N (2014) Proposal of a comprehensive definition of modified and other forms of mycotoxins including "masked" mycotoxins. Mycotoxin Res 30:197-205

Ryu D, Hanna MA, Bullerman LB (1999) Stability of zearalenone during extrusion of corn grits. J Food Prot 62:1482-1484

Samarajeewa U, Sen AC, Cohen MD, Wei CI (1990) Detoxification of aflatoxins in foods and feeds by physical and chemical methods. J Food Prot 53:489-501

Saunders D, Meredith F, Voss K (2001) Control of fumonisin: effects of processing. EnvironHealth Perspect 109:333-336

SCF, Scientific Committee for Food (2002) Opinion of the Scientific Committee on Food on Fusarium toxins. Part 6: Group evaluation of T-2 toxin, HT-2 toxin, nivalenol and deoxynivalenol (adopted on 
26 February 2002). http://ec.europa.eu/food/fs/sc/scf/out123_en. pdf. Accessed 16 July 2016

SCF, Scientific Committee for Food (2003) Updated opinion of the Scientific Committee on Food on fumonisin B1, B2 and B3. http://ec.europa.eu/food/fs/sc/scf/out185_en.pdf. Accessed 16 July 2016

Schilter B, Benigni R, Boobis A, Chiodini A, Cockburn A, Cronin MT, Lo Piparo E, Modi S, Thiel A, Worth A (2014) Establishing the level of safety concern for chemicals in food without the need for toxicity testing. Regul Toxicol Pharmacol 68:275-296

Schlüter O, Ehlbeck J, Hertel C, Habermeyer M, Roth A, Engel KH, Holzhauser T, Knorr D, Eisenbrand G (2013) Opinion on the use of plasma processes for treatment of foods. Mol Nutr Food Res 57: 920-927

Schollenberger M, Mueller H-M, Ruefle M, Drochner W (2008) Redistribution of 16 Fusarium toxins during commercial dry milling of maize. Cereal Chem 85:557-560

Schwake-Anduschus C, Langenkämper G, Unbehend G, Dietrich R, Märtlbauer E, Münzing K (2010) Occurrence of Fusarium T-2 and HT-2 toxins in oats from cultivar studies in Germany and degradation of the toxins during grain cleaning treatment and food processing. Food Addit Contam 27:1253-1260

Schwake-Anduschus C, Proske M, Sciurba E, Muenzing K, Koch M, Maul R (2015) Distribution of deoxynivalenol, zearalenone, and their respective modified analogues in milling fractions of naturally contaminated wheat grains. World Mycotoxin J 8:433-443

Schwartz HE, Hametner C, Slavik V, Greitbauer O, Bichl G, Kunz-Vekiru E, Schatzmayr D, Berthiller F (2013) Characterization of three deoxynivalenol sulfonates formed by reaction of deoxynivalenol with sulfur reagents. J Agric Food Chem 61:8941-8948

Schwartz PB, Casper HH, Beattie S (1995) Fate and development of naturally occurring Fusarium mycotoxins during malting and brewing. J Amer Soc Brew Chem 53:121-127

Schwarz PB, Hill NS, Rottinghaus GE (2007) Fate of ergot (Claviceps purpurea) alkaloids during malting and brewing. J Am Soc Brew Chem 65:1-8

Scott PM (1996) Mycotoxins transmitted into beer from contaminated grains during brewing. J Assoc Off Anal Chem Int 79:875-882

Scott PM, Kanhere SR, Weber D (1993) Analysis of Canadian and imported beers for Fusarium mycotoxins by gas chromatographymass spectrometry. Food Addit Contam 10:381-389

Scott PM, Lawrence GA (1982) Losses of ergot alkaloids during making of bread and pancakes. J Agric Food Chem 30(3):445-450

Scott PM, Lawrence GA (1994) Stability and problems in recovery of fumonisins added to corn-based foods. J Assoc Off Anal Chem Int 77:541-545

Scott PM, Lawrence GA (1995) Analysis of beer for fumonisins. J Food Protect 58:1379-1382

Scott PM, Trucksess MW (2009) Prevention of mycotoxins in dried fruit, other fruit products, and botanicals. ACS Symp Ser 1031:17-35

Scudamore KA (2005) Prevention of ochratoxins a in commodities and likely effects of processing fractionation and animal feeds. Food Addit Contam 1:17-25

Scudamore KA, Banks JN, Guy RCE (2004) Fate of ochratoxin a in the processing of whole wheat grain during extrusion. Food Addit Contam 21:488-497

Scudamore KA, Patel S (2000) Survey for aflatoxins, ochratoxin a, zearalenone and fumonisins in maize imported into the United Kingdom. Food Addit Contam 17:407-416

Scudamore KA, Guy RCE, Kelleher B, MacDonald SJ (2008) Fate of the fusarium mycotoxins, deoxynivalenol, nivalenol and zearalenone, during extrusion of wholemeal wheat grain. Food Addit Contam Part A 25:331-337

Seiferlein M, HumpfH-U, Voss KA, Sullards MC, Allegood JC, Wang E, Merrill AH (2007) Hydrolyzed fumonisins $\mathrm{HFB}_{1}$ and $\mathrm{HFB}_{2}$ are acylated in vitro and in vivo by ceramide synthase to form cytotoxic N-acyl-metabolites. Mol Nutr Food Res 51:1120-1130

el-Sharkawy S, Abul-Hajj YJ (1988) Microbial cleavage of zearalenone. Xenobiotica 18:365-371

Shephard GS, Berthiller F, Burdaspal P, Crews C, Jonker MA, Krska R, MacDonald S, Malone B, Maragos C, Sabino M, Solfrizzo M, Van Egmond HP, Whitaker TB (2011) Developments in mycotoxin analysis: an update for 2009-2010. World Mycotoxin J 4:3-30

Shephard GS, Marasas WFO, Burger H-M, Somdyala NIM, Rheeder JP, Van der Westhuizen L, Gatyeni P, Van Schalkwyk DJ (2007) Exposure assessment for fumonisins in the former Transkei region of South Africa. Food Addit Contam 24:621-629

Shetty PH, Bhat RV (1999) A physical method for segregation of fumonisin-contaminated maize. Food Chem 66:371-374

Siciliano I, Spadaro D, Prelle A, et al. (2016) Use of cold atmospheric plasma to detoxify hazelnuts from aflatoxins. Toxins. doi: 10.3390 /toxins 8050125

Simsek S, Burgess K, Whitney KL, Gu Y, Qian SY (2012) Analysis of deoxynivalenol and deoxynivalenol-3-glucoside in wheat. Food Control 26:287-292

Siwela AH, Siwela M, Matindi G, Dube S, Nziramasanga N (2005) Decontamination of aflatoxin-contaminated maize by dehulling. J Sci Food Agric 85:2535-2538

Slope SL, Wu S, Wu Z, Shen H, Chang XJ (2013) Patent CN 103205311B. A method for industrially removing zearalenone out of maize germ. State Grain Administration Institute (Granted 24 Dec 2014)

Smiley RD, Draughon FA (2000) Preliminary evidence that degradation of aflatoxin $\mathrm{B}_{1}$ by Flavobacterium aurantiacum is enzymatic. $\mathrm{J}$ Food Prot 63:415-418

Speijers GJA, van Egmond HP (1993) World-wide ochratoxin a levels in food and feeds. In: Creppy E, Castegnaro M, Dirheimer G (eds) Human Ochratoxicosis and its pathologies. John Libbey Eurotext Ltd., Paris, pp. 85-100

Sreenivasamurthy V, Parpia HAB, Srikanta S, Shankarmurti A (1967) Detoxification of aflatoxin in peanut meal by hydrogen peroxide. $\mathrm{J}$ Assoc Off Anal Chem Int 50:350-354

Stander MA, Bornscheuer UT, Henke E, Steyn PS (2000) Screening of commercial hydrolases for the degradation of ochratoxin a. J Agric Food Chem 48:5736-5739

di Stefano V, Pitonzo R, Avellone G (2014) Effect of gamma irradiation on aflatoxins and ochratoxin a reduction in almond samples. J Food Res 3:113-118

Suman M, Generotti S (2015) Transformation of mycotoxins upon food processing: masking, binding and degradation phenomena. In: Dall'Asta C, Berthiller F (eds) Masked mycotoxins in food: formation, occurrence and toxicological relevance. RSC Publishing, Cambridge, pp. 73-89

Suman M, Generotti S, Cirlini M, Malachova A, Berthiller F, Dall'Asta C (2014) Fate of mycotoxins along industrial biscuits and rusks processing, with deoxynivalenol and ochratoxin a as main targets, Proceedings of the International Mycotoxin Conference IMC2014 - Beijing, China, 19 to 23 May 2014

Suman M, Manzitti A, Catellani D (2012) A design of experiments approach to studying deoxynivalenol and deoxynivalenol-3-glucoside evolution throughout industrial production of whole grain crackers exploiting LCeMS/MS techniques. World Mycotoxin J 5:241-249

Suzuki T, Takeda M, Tanabe H (1971) A new mycotoxin produced by Aspergillus clavatus. Chem Pharm Bull 19:1786-1788

Sydenham EW, van der Westhuizen L, Stockenstrom S, Shephard GS, Thiel PG (1994) Fumonisin-contaminated maize: physical treatment for the partial decontamination of bulk shipments. Food Addit Contam 11:25-32

Takahashi-Ando N, Kimura M, Kakeya H, Osada H, Yamaguchi I (2002) A novel lactonohydrolase responsible for the detoxification of 
zearalenone: enzyme purification and gene cloning. Biochem J 365: $1-6$

Tan H, Hu Y, He J, Wu L, Liao F, Luo B, He Y, Zuo Z, Ren Z, Zhong Z, Peng G, Deng J (2014) Zearalenone degradation by two Pseudomonas strains from soil. Mycotoxin Res 30:191-196

Taylor MC, Jackson CJ, Tattersall DB, French N, Peat TS, Newman J, Briggs LJ, Lapalikar GV, Campbell PM, Scott C, Russell RJ, Oakeshott JG (2010) Identification and characterization of two families of F420 H2-dependent reductases from Mycobacteria that catalyse aflatoxin degradation. Mol Microbiol 78:561-575

ten Bosch L, Avramidis G, Döll K, Wienecke S, Karlovsky P, Viöl W (2014) Degradation of Fusarium mycotoxins deoxynivalenol and zearalenone by cold atmospheric pressure plasma. http://www. mycotoxin-workshop.de/36th_Mycotoxin_Workshop_2014_Proceedings.pdf. Accessed 16 July 2016

Teniola OD, Addo PA, Brost IM, Farber P, Jany KD, Jany KD, Alberts JF, van Zyl WH, Steyn PS, Holzapfel WH (2005) Degradation of aflatoxin B-1 by cell-free extracts of Rhodococcus erythropolis and Mycobacterium fluoranthenivorans sp. nov. DSM44556(T). Int J Food Microbiol 105:111-117

Teuber M (1993) Genetic engineering techniques in food microbiology and enzymology. Food Rev Int 9:389-409

Tibola CS, Cunha Fernandes JM, Guarienti EM, Nicolau M (2015) Distribution of Fusarium mycotoxins in wheat milling process. Food Control 53:91-95

Trenholm HL, Charmley LL, Prelusky DB, Warner RM (1991) Two physical methods for the decontamination of four cereals contaminated with deoxynivalenol and zearalenone. J Agric Food Chem 39: 356-360

Trenholm HL, Charmley LL, Prelusky DB, Warner RM (1992) Washing procedures using water or sodium carbonate solutions for the decontamination of three cereals contaminated with deoxynivalenol and zearalenone. J Agric Food Chem 40:2147-2151

Trivede AB, Doi E, Kitabatake N (1992) Cytotoxicity of citrinin heated at temperatures above $100{ }^{\circ} \mathrm{C}$. Biosci Biotech Biochim 56:423-426

Turcotte AM, Scott PM, Tague B (2013) Analysis of cocoa products for OTA and aflatoxins. Mycotoxin Res 29:193-201

Utermark J, Karlovsky P (2007) Role of zearalenone lactonase in protection of Gliocladium roseum from fungitoxic effects of the mycotoxin zearalenone. Appl Environ Microbiol 73:637-642

Vaclavikova M, Malachova A, Veprikova Z, Dzuman Z, Zachariasova M, Hajslova J (2013) "Emerging" mycotoxins in cereals processing chains: changes of enniatins during beer and bread making. Food Chem 136:750-757

Vanhoutte I, Audenaert K, De Gelder L (2016) Biodegradation of mycotoxins: tales from known and unexplored worlds. Front Microbiol 7: 561. doi:10.3389/fmicb.2016.00561

van Egmond HP, Schothorst RC, Jonker MA (2007) Regulations relating to mycotoxins in food: perspectives in a global and European context. Anal Bioanal Chem 389:147-157

van der Fels-Klerx HJ, Edwards SG, Kennedy MC, O’Hagan S, O'Mahony C, Scholz G, Steinberg P, Chiodini A (2014) A framework to determine the effectiveness of dietary exposure mitigation to chemical contaminants. Food Chem Toxicol 74:360-371

Velazhahan R, Vijayanandraj S, Vijayasamundeeswari A, et al. (2010) Detoxification of aflatoxins by seed extracts of the medicinal plant, Trachyspermum ammi (L.) Sprague ex Turrill—structural analysis and biological toxicity of degradation product of aflatoxin G1. Food Control 21:719-725. doi:10.1016/j.foodcont.2009.10.014

Vekiru E, Hametner C, Mitterbauer R, Rechthaler J, Adam G, Schatzmayr G, Krska R, Schuhmacher R (2010) Cleavage of zearalenone by Trichosporon mycotoxinivorans to a novel nonestrogenic metabolite. Appl Environ Microbiol 76:2353-2359

Vidal A, Marín S, Morales H, Ramos AJ, Sanchis V (2014) The fate of deoxynivalenol and ochratoxin a during the breadmaking process, effects of sourdough use and bran content. Food Chem Toxicol 68: $53-60$

Vijayanandraj S, Brinda R, Kannan K, Adhithya R, Vinothini S, Senthil K, Chinta RR, Paranidharan V, Velazhahan R (2014) Detoxification of aflatoxin B1 by an aqueous extract from leaves of Adhatoda vasica Nees. Microbiol Res 169:294-300. doi:10.1016/j. micres.2013.07.008

Villalobos MC, Serradilla MJ, Martín A, Pereira C, López-Corrales M, Córdoba MG (2016) Evaluation of different drying systems as an alternative to sun drying for figs. Innov Food Sci Emerg Technol 36: $156-165$

Visconti A, Haidukowski EM, Pascale M, Silvestri M (2004) Reduction of deoxynivalenol during durum wheat processing and spaghetti cooking. Toxicol Lett 153:181-189

Visconti A, Solfrizzo M, Doko MB, Boenke A, Pascale M (1996) Stability of fumonisins at different storage periods and temperatures in g-irradiated maize. Food Addit Contam 13:929-938

Voss KA, Smith GW, Haschek WM (2007) Fumonisins: toxicokinetics, mechanism of action and toxicity. Anim Feed Sci Technol 137:299 325

Voss KA, Snook ME (2010) Stability of the mycotoxin deoxynivalenol (DON) during the production of flour-based foods and wheat flake cereal. Food Addit Contam 27:1694-1700

Vučković J, Bodroža-Solarov M, Đura Vujić Đ, Bočarov-Stančić A, Bagi F (2013) Protective effect of hulls on the occurrence of Alternaria mycotoxins in spelt wheat. J Science Food Agric 93:1996-2001

Wang J, Ogata M, Hirai H, Kawagishi H (2011) Detoxification of aflatoxin $\mathrm{B} 1$ by manganese peroxidase from the white-rot fungus Phanerochaete sordida YK-624. FEMS Microbiol Lett 314:164 169

Wang JS, Luo H, Billam M, Wang Z, Guan H, Tang L, Goldston T, Afriyie-Gyawu E, Lovett C, Griswold J, Brattin B, Taylor RJ, Huebner HJ, Phillips TD (2005) Short-term safety evaluation of processed calcium montmorillonite clay (NovaSil) in humans. Food Addit Contam 22:270-279

Wang P, Afriyie-Gyawu E, Tang Y, Johnson NM, Xu L, Tang L, Huebner HJ, Ankrah NA, Ofori-Adjei D, Ellis W, Jolly PE, Williams JH, Wang JS, Phillips TD (2008) NovaSil clay intervention in Ghanaians at high risk for aflatoxicosis: II. Reduction in biomarkers of aflatoxin exposure in blood and urine. Food Addit Contam 25: $622-634$

Weng CY, Martinez AJ, Park DL (1994) Efficacy and permanency of ammonia treatment in reducing aflatoxin levels in corn. Food Addit Contam 11:649-658

Whitaker TB, Dorner JW, Lamb M, Slate AB (2005) The effect of sorting farmers' stock peanuts by size and color on partitioning aflatoxin into various shelled peanut grade sizes. Peanut Sci 32:103-118

Whitaker TB, Richard JL, Giesbrecht FG, Slate AB, Ruiz N (2003) Estimating deoxynivalenol in shelled corn barge lots by measuring deoxynivalenol in corn screenings. J Assoc Off Anal Chem Int 86: $1187-1192$

Whitehurst RJ, van Oort M (2010) Enzymes in food technology. WileyBlackwell, Singapore

Wolf-Hall CE, Schwarz PB (2002) Mycotoxins and fermentation-beer production. In: DeVries JW, Trucksess MW, Jackson LS (eds) Mycotoxins and food safety. Springer, New York, pp. 217-226

Wood GM (1982) Effects of processing on mycotoxins in maize. Chem Ind 972:1982

Wu Q, Lohrey L, Cramer B, Yuan Z, Humpf HU (2011) Impact of physicochemical parameters on the decomposition of deoxynivalenol during extrusion cooking of wheat grits. J Agric Food Chem 59: $12480-12485$

Yagen B, Hutchins JE, Cox RH, Hagler WM, Hamilton PB (1989) Aflatoxin $\mathrm{E}_{1} \mathrm{~S}$ : revised structure for the sodium sulfonate formed by destruction of aflatoxin $\mathrm{B}_{1}$ with sodium sisulfite. J Food Prot 52:574-577 
Yahl KR, Watson SA, Smith RJ, Barabolok R (1971) Laboratory wetmilling of corn containing high levels of aflatoxin and a survey of commercial wet-milling products. Cereal Chem 48:385-391

Yoshizawa T, Takeda H, Ohi T (1983) Structure of a novel metabolite from deoxynivalenol, a trichothecene mycotoxin, in animals. Agric Biol Chem 47:2133-2135

Young JC, Chen ZJ, Marquardt RR (1983) Reduction in alkaloid contenet of ergot sclerotia by chemical and physical treatment. J Agric Food Chem 31:413-415

Young JC (1986) Reduction in levels of deoxynivalenol in contaminated corn by chemical and physical treatment. J Agric Food Chem 34: 465-467

Young JC, Subryan LM, Potts D, McLaren ME, Gobran FH (1986) Reduction in levels of deoxynivalenol in contaminated wheat by chemical and physical treatment. J Agric Food Chem 34:461-465

Young JC, Trenholm HL, Friend DW, Prelusky DB (1987) Detoxification of deoxynivalenol with sodium bisulfite and evaluation of the effects when pure mycotoxin or contaminated corn was treated and given to pigs. J Agric Food Chem 35:259-261
Yousef AE, Marth EH (1989) Stability and degradation of aflatoxin M1. In: Egmond HP (ed) Mycotoxins in dairy products. Elsevier, London, pp. 127-162

Zachariasova M, Vaclavikova M, Lacina O, Hajslova JJ (2012) Deoxynivalenol oligoglycosides: new "masked" fusarium toxins occurring in malt, beer, and breadstuff. J Agric Food Chem 60: 9280-9291

Zhang H, Li J (1994) Detoxification of moniliformin. Acta Microbiol Sin 34:119-123

Zhu R, Feussner K, Wu T, Yan F, Karlovsky P, Zheng X (2015a) Detoxification of mycotoxin patulin by the yeast Rhodosporidium paludigenum. Food Chem 179:1-5

Zhu R, Yu T, Guo S, Hu H, Zheng X, Karlovsky P (2015b) Effect of the yeast Rhodosporidium paludigenum on postharvest decay and patulin accumulation in apples and pears. $\mathrm{J}$ Food Prot 78:157-163

Zhu Y, Koutchma T, Warrinner K, Zhou T (2014) Reduction of patulin in apple juice products by UV light of different wavelengths in the UVC range. J Food Prot 77:963-967 